LIAMES, Campinas, SP, v. 19, 1-35, e019016, 2019

\title{
Explorações sobre padrões de indexação e classificação nominal de argumentos em línguas indígenas da América do Sul
}

\author{
Thiago Costa Chacon \\ Universidade de Brasília, Brasil \\ https://orcid.org/0000-0002-6355-3505 \\ Rodrigo do Prado Sateles \\ P.G. Universidade de Brasília, Brasil \\ https://orcid.org/0000-0002-6593-3894
}

\begin{abstract}
This work presents the first results of a typological survey of South American indigenous languages that aims at analyzing the patterns by which arguments of a sentence are indexed by nominal classification systems. With a geographically and phylogenetically diverse sample of languages, and building on theoretical discussion about what are nominal classification systems, we restrict our observation to languages that classify arguments beyond deictic (as person) and quantitative semantic dimensions (such as number), focusing on systems such as gender, noun classes, and classifiers. We explore the different formal and semantic ways in which arguments can be indexed, seeking generalizations between types of nominal classification systems and correlations with other nominal categories expressed by verbs or predicates. We also explore some Greenbergian generalizations about the relationship between nominal classification patterns in verbs and in the noun phrase. As a result, we find a set of properties that serve to typologically distinguish systems of gender, noun classes and classifiers. We argue that the typological differences among these systems were shaped by distinct diachronic forces, starting with the distinct diachronic sources of gender, classifiers and noun classes systems.

KEYwORDS: Nominal classification: Indexation; Argument; Diachronic typology..
\end{abstract}

RESUMO: Este trabalho apresenta os primeiros resultados de uma pesquisa tipológica sobre padrões de classificação nominal em línguas indígenas da América do Sul. Mais especificamente analisamos os padrões pelos quais argumentos de uma oração podem ser indexados por morfemas que os categorizam para além de dimensões semânticas dêiticas (como pessoa) e quantitativas (como número), focando em sistemas como gênero, classes nominais e classificadores. A partir de uma amostragem geográfica e filogeneticamente diversificada de línguas do continente, e uma discussão teórica sobre o que é classificação nominal e indexação de argumentos, como objetivos principais, procuramos explorar as diferentes maneiras formais e semânticas como argumentos podem ser indexados, buscando generalizações entre tipos de sistemas de classificação nominal e sua correlação com outras categorias nominais expressas por verbos ou predicados. Também exploramos algumas generalizações greenberguianas entre padrões de classificação nominal nos verbos, no sintagma nominal e na palavra nominal. Como resultado, encontramos um conjunto de propriedades que servem para distinguir em um plano tipológico sistemas de gênero, classes nominais e classificadores. Argumentamos que essas diferenças tipológicas foram moldadas por forças diacrônicas distintas, a começar pela fonte dos sistemas de gênero, que são morfemas 
dêiticos como pronomes livres e demonstrativos, em contraste com compostos nominais que são a fonte dos sistemas de classificadores e classes nominais.

PALAVRaS CHAVE: Classificação nominal; Concordância; Argumento; Tipologia diacrônica; Indexação.

\section{Introdução}

Os sistemas de classificação nominal (SCN) são um dos temas da tipologia linguística mais amplamente estudados ao longo da história (ver Kilarski 2013 para uma revisão histórica). Ainda assim, alguns pontos permanecem mal resolvidos no plano terminológico e há ainda algumas áreas mal compreendidas, como por exemplo os SCN de muitas línguas da América do Sul e a interação entre SCN e diferentes componentes gramaticais e seu uso no discurso (Grinevald 2000, 2015; Aikhenvald 2000; Contini-Morava e Kilarski 2013). Este trabalho procura abordar algumas dessas áreas menos compreendidas, focando em 23 línguas da América do Sul (ver mapa na figura 1), com o objetivo central de explorar possíveis correlações entre os padrões de indexação de argumentos de uma oração, os tipos de SCN e sua expressão nas relações gramaticais dentro do sintagma nominal (SN). O procedimento analítico que utilizamos foi

1. definir protótipos de SCN (seção 3);

2. buscar generalizações/implicações tipológicas sobre a relação entre esses sistemas, os índices verbais e as propriedades do SN (seção 4);

3. analisar casos que fogem ligeiramente às generalizações/implicações observadas na seção 4 (seção 5.1 e 5.2);

4. procurar explicações para os casos que se conformam com as generalizações/ implicações observadas na seção 4 (seção 5.3).

A seção 2 deste artigo aborda a natureza teórica dos problemas que estamos lidando ao discutir o que entendemos por indexação de argumentos de um predicado, o que são SCN, os principais estudos tipológicos sobre SCN de línguas da América do Sul, bem como algumas correlações entre o predicado e o SN no que tange os SCN. Na seção 3 apresentamos nossa metodologia, detalhando a natureza do nosso corpus, nossa definição dos tipos de SCN e os parâmetros tipológicos de análise. A seção 4 traz o conjunto de resultados e generalizações. Na seção 5 discutimos esses resultados mais detalhadamente e exploramos possíveis explicações para os fenômenos encontrados. A seção 6 conclui o presente artigo. 
Figura 1: Mapa elaborado pelos autores com a distribuição das línguas e suas famílias linguísticas (ver apêndice para mais informações sobre as línguas).

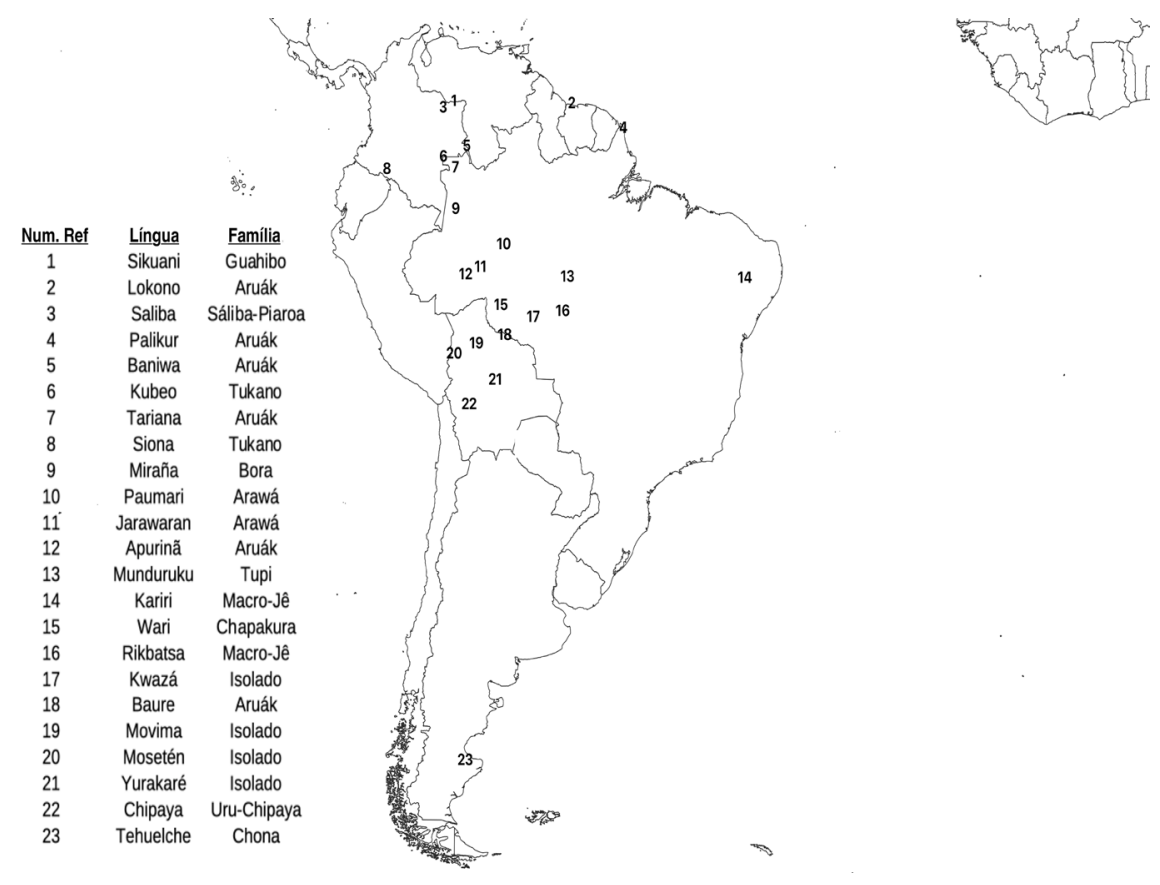

\section{Definição do problema: Indexação e classificação nominal}

Nessa seção, iremos analisar aspectos tipológicos sobre a noção de indexação e classificação nominal, procurando levantar os principais mecanismos e problemas que serão abordados pela metodologia da nossa pesquisa na seção 3 .

\subsection{Indexação e a classificação semântica dos argumentos de um predicado}

O problema central que analisamos neste artigo é o cruzamento entre $\mathrm{SCN}$ e a indexação de argumentos de uma oração. É notável que na literatura tipológica sobre a classificação nominal, salvo pelos chamados "classificadores verbais" (ver seção 2.2 e 3), os verbos não figuram como um locus privilegiado.

Os verbos podem classificar seus argumentos a partir de duas estratégias principais: índices morfossintáticos e por seleção lexical. ${ }^{1}$ Quando analisamos os índices morfossintáticos, é importante compreender a relação semântica e sintática que o índice

${ }^{1}$ Essa última estratégia não nos interessa diretamente, mas cabe mencionar exemplos como os verbos em alemão para "comer" que diferenciam um agente humano ("essen") de não-humano ("fressen"), ou os verbos que funcionam como núcleo de predicados não-verbais na língua Ika (família Chibcha) e que classifica o sujeito de acordo com suas propriedades físicas e posturais (Aikhenvald 2000: 156). 
desempenha com relação ao verbo e com relação a um nome correspondendo à expressão lexical de seu argumento numa mesma oração. Semanticamente, não é raro encontrarmos índices que classificam seus argumentos qualitativamente para além de categorias dêiticas (como pessoa) ou quantitativas (como número), abrangendo noções típicas dos SCN como sexo (gênero), animacidade, humanidade, propriedades físicas, posturais e utilidade (cf. Denny 1976; Aikhenvald 2000). Para uma abordagem inicial ao problema, faz sentido, então, tratarmos essa dimensão semântica qualitativa como independente de número e pessoa, ainda que os sistemas específicos possam expressar essas categorias conjuntamente.

Além disso, enquanto a relação do índice com o argumento é em geral tratada como concordância ou referência-cruzada ("cross-reference") na literatura, achamos oportuno a distinção apresentada por Haspelmath (2013) que classifica as relações de "concordância" de acordo com três configurações morfossintáticas do índice, sendo elas: gramm-index (quando o índice verbal é obrigatório bem como a expressão sintática do argumento), cross-index (quando o índice verbal é obrigatório e a expressão sintática do argumento é opcional) e pro-index (quando o índice e a expressão sintática do argumento estão em distribuição complementar).

A análise que Corbett (2006) faz sobre a estrutura da relação de concordância propõe que exista um elemento controlador, um elemento alvo (ou "target", onde se realiza formalmente a concordância) e um domínio, i.e a relação gramatical estabelecida entre controlador e alvo. Por exemplo, no sintagma As menina bonita (falado em muitas variedades do Português do Brasil) podemos dizer que o controlador é 'menina', os alvos são o artigo 'As' e o adjetivo 'bonita'. As marcas de gênero e número tem como domínio a relação dentro do SN entre o nome núcleo e seus modificadores, porém, enquanto gênero possui mais de um alvo, número possui apenas um alvo, i.e. o artigo. A marca de plural no artigo evidencia ainda um aspecto especial da concordância: em certos casos uma marca flexional pode estar formalmente presente no alvo, mas ausente no controlador.

Seguimos Bickel (2010) ao entender que os argumentos possuem relações gramaticais com tipos específicos de construções ou regras. No exemplo anterior do sN, temos uma construção referente à concordância de gênero (com dois alvos) e outra referente à concordância de número (com apenas um alvo). No domínio da oração, o controlador é o argumento, o alvo podem ser marcas flexionais verbais, clíticos, etc. A relação gramatical dos argumentos de uma oração é formalizável pelas seguintes notações que indicam o macro-papel semântico de um argumento frente ao predicado:

- A: argumento agente ou semanticamente mais próximo a um agente em verbos transitivos

- O: argumento paciente ou semanticamente mais próximo a um paciente em verbos transitivos

- S: único argumento de um verbo intransitivo ( $S o$ se este argumento apresenta propriedades similares a $\mathrm{O}$, ou $\mathrm{Sa}$ se, a A).

- T: argumento paciente ou semanticamente mais próximo a um paciente em verbos ditransitivos

- G: argumento recipiente ou semanticamente mais próximo a um recipiente em verbos ditransitivos 
A maneira como cada construção seleciona um argumento se traduz nos chamados sistemas de alinhamento como nominativo-acusativo, ergativo-absolutivo, etc. Ao entender que certos SCN possuem a oração como um domínio, podemos tratar esses SCN como uma construção específica que indexa os argumentos em diferentes padrões de alinhamentos e domínios (ver seção 4.3).

\subsection{Sistemas de classificação nominal}

Um dos resultados da pesquisa tipológica no final do século xx foi chegar à definição de um conjunto finito de SCN, apresentados com base em dois módulos: sistemas lexicais e sistemas morfossintáticos (Allan 1977; Grinevald 2000; Aikhenvald 2000). Segundo essas propostas, os SCN morfossintáticos poderiam ser divididos entre sistemas de classificadores, classes nominais $(\mathrm{CN})$ e gênero.

A noção de gênero é a mais tradicional para estudiosos de línguas europeias e é definida a partir de dois elementos fundamentais: a noção de concordância e a definição dos traços semânticos que compõem estes sistemas (Corbett 1991). Com relação à concordância, os sistemas de CN seriam tipologicamente indistintos aos sistemas de gênero, pois ambos são definidos por essa mesma propriedade. Assim, segundo Corbett (1991) 'the use of 'gender' or 'noun class' is also more a matter of tradition than of substance (...) The choice is not important; for consistency, we shall normally use the term "gender" (Corbett 1991: 10).

No entanto, outras propostas sublinham certas diferenças entre gênero e classes nominais. Para Dixon (1968: 105), “[g]ender can be regarded as a particular instance of 'noun class', when there are just two or three classes and considerable semantic correlation with sex". Já Serzisko (1982) considera gênero e CN dentro de um mesmo contínuo de técnicas de classificação nominal e os diferencia com base em diferentes parâmetros, tais como: (1) a quantidade de classes semânticas de cada sistema, ${ }^{2}$ (2) o fato de nos sistemas de $\mathrm{CN}$ a expressão de número e da classe nominal serem sempre fusionadas, (3) o fato de que as CN se expressam não só sintaticamente em alvos de concordância, mas também na morfologia flexional e derivacional nominal, e (4) pelo fato de CN serem, em geral, semanticamente mais transparentes às propriedades dos referentes nominais do que as marcas de gênero em línguas europeias (ver também a discussão de Allan [1977: 290-1] sobre gênero e os chamados "concordial classifiers" [o que inferimos serem o que outros chamaram de CN com base nos seus exemplos de línguas Banto e Australianas]).

Diferentemente dos sistemas de gênero e CN, os classificadores, segundo tipologias de Allan (1977); Dixon (1986); Grinevald (2000, 2015) e Aikhenvald (2000), são morfemas que ocorrem em determinados ambientes sintáticos prototípicos, relativos a determinadas funções semânticas, como: classificadores genitivos (encontrados em construções possessivas), classificadores numerais (encontrados com numerais), classificadores nominais (encontrados como constituintes do SN e funcionando como determinantes ou

${ }^{2}$ Gênero tendo até 3 classes limitadas a categorias como sexo, animacidade e humano vs. não-humano, $\mathrm{CN}$ tendo 5 ou mais classes, podendo abarcar as categorias de gênero e essencialmente indo além destas (ver seção 3). 

pronomes anafóricos), classificadores dêiticos (encontrados junto a demonstrativos) e classificadores verbais (encontrados incorporados aos verbos núcleos de predicados).

Entre os tipos de classificadores acima, os classificadores verbais são os que nos interessam mais diretamente. Como resume Aikhenvald (2000), nesses sistemas (i) os classificadores aparecem no verbo e caracterizam o referente do seu argumento (forma, consistência, tamanho, animacidade, etc.); (ii) normalmente se referem aos argumentos $\mathrm{S}$ e/ou O, que podem estar presentes na mesma oração como SN independentes; (iii) sua escolha é mais condicionada a uma seleção lexical que um acordo gramatical, e em muitos casos o uso do classificador não é obrigatório; (iv) os nomes podem não estar associados a um classificador, assim como podem se associar a mais de um; (v) podem ser limitados a um certo número de verbos, de acordo com a semântica desses.

De fato, assim como vimos para a diferença entre gênero vs. CN, a diferença entre classificadores vs. gênero/CN também combina elementos categóricos com elementos mais gradativos, reforçando a ideia de que no fundo estamos tratando de um mesmo fenômeno ('classificação nominal') porém com manifestações variáveis e distinções gradativas. Essa noção de gradação dentro de um continuum de múltiplas variáveis está na base da tipologia de Serzisko (1982), Dixon (1986) e Grinevald (2000). Vejamos, por exemplo, a distinção entre classificadores e gênero/CN, resumida na tabela 1.

Tabela 1: Gênero vs. sistemas de classificador (Dixon 1986)

\begin{tabular}{|l|l|}
\hline Gênero/Classe Nominal & Classificadores \\
\hline Classifica todos os nomes & não classifica todos os nomes \\
\hline tendência a um pequeno número de classes & número maior de classes \\
\hline sistema fechado & sistema aberto \\
\hline fusionado com outras categorias gramaticais & constituinte independente \\
\hline pode estar marcado no nome & não afixado a um nome \\
\hline realizado com padrões de concordância & marcado uma só vez \\
\hline $\begin{array}{l}\text { O nome pertence a uma só classe sem variação do } \\
\text { falante }\end{array}$ & pode pertencer a várias classes dependendo do falante \\
\hline sem variação de registro & usos formais e informais \\
\hline
\end{tabular}

É um consenso hoje em dia entre os estudiosos do assunto que muitas línguas apresentam sistemas menos prototípicos ou ambíguos com relação a seu status como gênero, $\mathrm{CN}$ e classificadores. Por exemplo, uma situação intermediária entre classificadores verbais e gênero pode ser vista na língua Mawng, falada no norte da Austrália. Segundo Singer (2016), existem 5 "gêneros" nesta língua: Masculino, Feminino, Vegetação, Comestível e Geografia. Concordam com nomes em gênero os pronomes, demonstrativos, artigos, modificadores atributivos e verbos. Em verbos intransitivos, prefixos indexam o argumento $\mathrm{S}$ em um dos cinco gêneros, enquanto verbos transitivos indexam o argumento $\mathrm{A}$ em apenas dois gêneros: masculino e não-masculino. $\mathrm{O}$ mais interessante, no entanto, é que um nome pode controlar diferentes tipos de concordância com um gênero dependendo do status de seu referente. Em termos semânticos, essa recategorização de um nome com base em transformações dos referentes nominais é mais típica de sistemas de classificadores. 
Em muitas línguas sul-americanas, essas situações intermediárias são bastante comuns. A literatura tipológica traz diferentes soluções para esta questão, como Grinevald e Seifart (2004) que trataram esses sistemas como tipos de CN menos gramaticalizados, intermediários entre a natureza mais lexical de classificadores e mais gramatical de $\mathrm{CN}$. Por outro lado, outros tratam esses sistemas como classificadores (algo reminescente da noção de "concordial classifiers" de Allan 1977), notando seu caráter suis generis por ocorrerem em "múltiplos ambientes" (Aikhenvald 2000) e desempenharem "múltiplias funções" (Krasnoukhova 2012).

Em nossa amostra, encontramos línguas com sistemas diversos, que vão desde casos mais prototípicos de classificadores verbais ou gênero (e.g. Palikur e Lokono, respectivamente) a casos intermediários como por exemplo o Mundurukú, Kwazá e o Apurinã em que um mesmo conjunto de classificadores ocorre como classificadores verbais e em diferentes modificadores do SN (os chamados classificadores "multifuncionais" por Krasnoukhova 2012). Há também línguas que combinam mais de um sistema, um deles restrito ao SN e outro abrangendo a indexação de argumentos verbais além do SN (e.g. Kubeo, Baniwa), ou ambos ocorrendo no SN e no predicado (e.g. Movima). Na seção 3 apresentaremos nossa abordagem metodológica para dar conta desses fenômenos.

\subsection{Estudos sobre padrões de indexação e classificação de argumentos na América do Sul}

O conhecimento sobre as línguas da América do Sul tem uma entrada um pouco tardia nos estudos tipológicos. Com relação à classificação nominal e padrões de indexação dos argumentos, especificamente, apenas recentemente tivemos trabalhos que realmente abrangessem o continente numa escala que faz jus à diversidade das línguas sulamericanas. Nessa seção vamos apresentar três destes principais estudos e notar os pontos de contato que eles apresentam com este trabalho.

Em sua análise sobre os sistemas de classificação nominal em línguas sulamericanas, Regúnaga (2012) define cada sistema conforme suas características prototípicas, sobretudo semânticas, mantendo, assim, as distinções entre classificadores, CN e gênero. Seu trabalho é importante ao realçar também os chamados sistemas mistos, i.e., os casos de línguas que possuem mais de um sistema de classificação nominal. Segundo a autora, temos línguas com as seguintes configurações de sistemas: línguas com gênero, com gênero e CN, com gênero e classificadores, e com gênero, classificadores e CN.

Birchall (2014) analisou os padrões de marcação de argumentos em 95 línguas sulamericanas. Um dos parâmetros analisados pelo autor foi a expressão de gênero/ $\mathrm{CN}^{3}$ nos índices argumentais encontrados em verbos, descartando os sistemas de classificadores. Segundo sua pesquisa, quase todas as línguas que possuem gênero/CN como um traço gramatical dos nomes indexam pelo menos um dos argumentos verbais com base nos traços semânticos de seu SCN. Há línguas em que a expressão do SCN se dá de modo independente de outras categorias verbo-nominais como pessoa e número (e.g. Miraña),

${ }^{3} \mathrm{O}$ conceito de classe nominal usado por Birchall não coincide necessariamente com o uso deste termo neste artigo. Ver seção 3 . 
mas é relevante notar que até $77 \%$ dos índices verbais fundem a expressão de gênero/ CN com pessoa e número (2014: 52), não havendo casos em que gênero e número se fundem sem que a expressão de pessoa faça parte também da semântica desses índices (2014: 65). Em sua base de dados (Birchall 2016), 16 línguas foram identificadas como tendo gênero/CN, sendo que 13 apresentam classificação nominal de argumentos verbais, conforme resumido pela tabela 2 em que cruzamos classificação nominal com o macropapel semântico do argumento:

Tabela 2: Número de línguas com gênero/CN no SN e nos índices verbais em Birchall (2016)

\begin{tabular}{|l|l|l|l|l|l|l|}
\hline \multirow{2}{*}{} & \multirow{2}{*}{ No SN } & \multicolumn{5}{|c|}{ Nos Índices Verbais } \\
\cline { 3 - 8 } & & $\mathrm{A} / \mathrm{S}$ & $\mathrm{A} / \mathrm{S} / \mathrm{O}$ & $\mathrm{A} /$ Sa vs. O/So & $\mathrm{S} / \mathrm{O}$ & $\mathrm{O}$ \\
\hline Línguas com gênero/CN & 16 & 4 & 3 & 4 & 0 & 2 \\
\hline
\end{tabular}

Vemos que todas as línguas que classificam seus argumentos por meio de índices verbais também possuem um sistema de gênero/CN no $\mathrm{SN}$, ainda que o contrário não se observa. A tabela 2 mostra que os índices verbais com classificação nominal são principalmente encontrados em sistemas de alinhamento nominativo (A/S) - nas línguas Kubeo, Desano, Tariana, Bora, todas faladas no Noroeste Amazônico), alinhamento direto (A/S/O - nas línguas Movima, Wari, Jarawara [Jamamadí], todas do Sudoeste Amazônico) e ativo-estativo (A/Sa vs. O/So - em línguas da família Aruák: Baure, Apurinã e Lokono). As línguas com índices que classificam os argumentos com base em um alinhamento absolutivo ( $\mathrm{S} / \mathrm{O}$ ) estão ausentes na base de Birchall e apenas duas línguas marcam exclusivamente o argumento $\mathrm{O}$ (Yurakaré e Tehuelche). Iremos revisar esses dados na seção 4 e 5.

Krasnoukhova (2012) é até o momento o estudo tipológico mais abrangente das propriedades do SN em línguas sul-americanas. A autora analisou 55 línguas pertencentes a cerca de 35 famílias linguísticas (ou línguas isoladas) e geograficamente dispersas em todos os cantos do continente. Para o estudo da estrutura do SN, Krasnoukhova (2012: 7) focou nas relações entre nomes, demonstrativos, construções de posse, numerais e adjetivos ("property words"), o que - com exceção dos pronomes livres - corresponde exatamente ao que estaremos analisando neste trabalho. Com relação à indexação de argumentos verbais, Krasnoukhova nos oferece as seguintes generalizações:

(1) a maioria das línguas que usam afixos pessoais para indexar o possuidor junto a um nome possuído ("head-marking") também usa os mesmos afixos para indexar os argumentos junto aos verbos núcleos de predicados (2012: 60).

(2) em línguas com afixos/clíticos combinados ao possuidor e que indexam propriedades semânticas do nome possuído, apenas duas línguas, Mosetén e Jarawara, marcam concordância de gênero entre esse afixo/clítico de posse o nome possuído (2012: 63).

(3) Línguas com classificadores verbais e muitas das línguas com os chamados classificadores "multifuncionais" indexam certos argumentos (em geral em função So/O) com esses classificadores incorporados a verbos. 
O presente estudo parte, então, destes estudos anteriores com o objetivo de revisitar suas análises e propor uma abordagem metodológica integrada para o estudo dos padrões de classificação nominal no predicado e no SN. Ao incluir o que aqui chamamos de CN, preenchemos uma lacuna no trabalho de Birchall (2014), ao mesmo tempo que incluímos os sistemas de classificadores "multifuncionais" propostos por Krasnoukhova (2012). Nossa proposta tipológica se aproxima da de Regúnaga (2012) ao reconhecer os tipos tradicionais de SCN, porém acreditamos que apresentamos critérios mais explícitos - e às vezes divergentes dos da autora - para analisar e classificar os diferentes sistemas.

\subsection{Universais greenberguianos}

A relevância de integrar observações sobre a classificação nominal no predicado e no SN foi notada já pelos trabalhos sobre tipologia de Greenberg (1963), que apontou para as seguintes implicações (ou relações de dependência) entre os dois domínios:

Universal 30: Se um verbo possui categorias de pessoa-número ou gênero, ele sempre terá categorias de tempo e modo.

Universal 31: Se um verbo concorda com o sujeito ou objeto em gênero, então o adjetivo também sempre concorda com o nome em gênero.

Universal 32: Sempre que um verbo concorda com o sujeito ou objeto em gênero, ele também concorda em número.

Greenberg (1963: 93) ainda nota a seguinte tendência estatística: “a concordância de gênero entre um nome (em geral, o sujeito) e um verbo é bem menos frequente do que concordância em pessoa e número".

Um dos nossos objetivos será testar essas generalizações com nossa base de dados, com exceção para o universal 30 , para o qual não temos dados no momento. Adicionalmente, vamos investigar outras correlações possíveis entre padrões de indexação e categorização entre o núcleo do predicado e seus argumentos.

\section{Materiais e métodos}

Para a realização deste estudo, selecionamos ao todo 23 línguas, pertencentes a 11 famílias linguísticas e 4 línguas isoladas, conforme o mapa da figura 1. A amostragem foi realizada inicialmente a partir de fontes secundárias de informação, como Aikhenvald (2000); Regúnaga (2012); Krasnoukhova (2012) e Birchall (2014), seguida por uma consulta às fontes primárias de informações (ver citações no apêndice e seção de referências). Procuramos diversificar nossa amostra por diferentes regiões geográficas e famílias linguísticas (ou línguas isoladas) do continente, ainda que algumas regiões (e.g. Noroeste e Sudoeste Amazônico) ou famílias (e.g. Aruák) tenham sido mais representadas do que outras. Isso se deve, em certa medida, à própria preponderância de $\mathrm{SCN}$ nessas regiões e famílias linguísticas.

Delimitamos nossa observação a certos domínios morfossintáticos que são recorrentes tipologicamente na caracterização dos sistemas de classificação nominal, a 


\section{CHACON \& PRADO SATELES - EXPLORAC̄õES SOBRE PADRÕES...}

saber: Nomes, Pronomes livres (ou enfáticos), Numerais, Demonstrativos, Adjetivos, Construções Possessivas, e predicado.

Com relação aos índices dos argumentos verbais, estivemos restritos a no máximo dois paradigmas que tivessem organizações semânticas distintas. Limitamos nossa observação a predicados verbais finitos, na voz ativa, no modo declarativo e não marcados no que tange modalidade deôntica e epistêmica. Os índices dos argumentos foram classificados conforme os seguintes parâmetros:

- Classificação Semântica: masculino, feminino, neutro, animado, inanimado, humano, não-humano, propriedades físicas e utilidade.

- Pessoa: $1^{\mathrm{a}}, 2^{\mathrm{a}}$ e $3^{\mathrm{a}}$ pessoa.

- Número: singular, dual, plural ou não-singular.

- Macro-papel semântico do argumento: A (agente de verbo transitivo), O (paciente de verbo transitivo), S (argumento de verbo intransitivo), Sa (argumento de verbo intransitivo ativo) e So (argumento de verbo instransitivo estativo).

- Forma: pro-clíticos, prefixos, sufixos, enclíticos, formas livres dentro do predicado e incorporação nominal.

- Tipo de indexação: gramm-index, cross-index ou pro-index.

Com o objetivo de analisar as propriedades dos índices verbais e sua relação com os SCN, elaboramos uma definição dos tipos de SCN seguindo a ideia de protótipos de SCN, baseados num conjunto de propriedades que, ao mesmo tempo que permita certa sobreposição, também confere um conjunto mínimo e único para a definição de sistemas de gênero, CN, classificadores verbais e outros tipos de classificadores (cf. seção 2.2 e tabela 3). Os sistemas específicos que atribuímos a cada protótipo (ver apêndice) tendem a possuir o conjunto de propriedades características de cada protótipo de SCN, ainda que alguns sistemas específicos possam divergir do protótipo em certa medida, como veremos nas seções 4 e 5 . Isso é esperado e decorre da própria natureza da aplicação da teoria de protótipos na análise linguística (ver por exemplo Givón 1986). ${ }^{4}$

A definição desses protótipos levou em consideração três tipos de propriedades: o número de categorias semânticas de um sistema, o conteúdo semântico dessas categorias e a distribuição morfossintática da expressão formal dessas categorias. Assim, sob um ponto de vista semântico, definimos como sistemas de gênero aqueles que possuam categorias como sexo, humanidade e/ou animacidade. Nesse ponto, gênero se opõe aos demais sistemas (classificadores e $\mathrm{CN}$ ), nos quais os nomes são crucialmente categorizados por parâmetros semânticos obrigatórios como propriedades físicas e/ou utilidade. Categorias como sexo, humanidade e animacidade podem estar presentes nos demais sistemas, porém não são cruciais para defini-los.

${ }^{4}$ A noção de protótipo que usamos aqui advém da psicologia cognitiva e linguística tipológico-functional. Como define Givón (1986: 79): “(...) natural cognitive and linguistic categories are not always — and perhaps are seldom - defined in terms of a single or a few, criterial ('sufficient and necessary') properties. Rather, categories within the continuum-space are formed at intersections of a number — sometime many — " characteristic" or "typical" features/properties, properties that tend to coincide statistically/probabilistically, but do not always coincide absolutely." 
Com relação ao número de categorias semânticas, todos os sistemas possuem logicamente um número mínimo de duas categorias. A diferença entre os sistemas reside no número máximo de categorias: para gênero esse número é extremamente restrito, possuindo no máximo três categorias. Já os demais sistemas possuem um número máximo irrestrito de categorias, podendo variar de duas categorias a algumas dezenas.

Com relação aos ambientes morfossintáticos, nossa tipologia se baseou nos seguintes parâmetros com relação à função dos morfemas de classificação nominal como: (1) formativos dos nomes; (2) índices em um, dois ou mais posições/constituintes do SN para além dos nomes (i.e. pronomes, demonstrativos, adjetivos, numerais, construções possessivas); (3) índices no predicado. Além de observar o ambiente específico (nome, constituintes do SN e predicado), também definimos cada sistema com base em critérios distributivos, i.e. se os morfemas de classificação nominal devem estar: (i) necessariamente presentes em um dado ambiente; (ii) necessariamente ausentes em um dado ambiente; (iii) ou se a presença ou ausência desses morfemas é opcional, ou seja não interfere na definição tipológica de um dado protótipo de sistema. ${ }^{5}$ Seguindo esses dois tipos de parâmetros morfossintáticos, obtivemos a seguinte definição de cada sistema:

(1) Gênero: há necessariamente morfemas de classificação em gênero em pelo menos um constituinte do SN. Nos nomes e no predicado a ocorrência desses morfemas é opcional.

(2) CN: há necessariamente morfemas de CN nos nomes (ou em boa parte dos nomes) e em pelo menos um constituinte do SN fora os nomes. É opcional sua presença como índice nos predicados.

(2) Classificadores Verbais: ocorrem obrigatoriamente incorporados aos verbos (ou em boa parte dos verbos), e devem estar obrigatoriamente ausentes em quaisquer outros ambientes.

(4) Outros Classificadores: são caracterizados pela presença obrigatória de morfemas associados a um ambiente específico, do qual se depreende sua função primária como classificadores numerais, genitivos ou nominais; podem estar opcionalmente presentes nos nomes ou em no máximo um outro constituinte do $\mathrm{SN}^{6}{ }^{6}$ estão necessariamente ausentes do predicado.

${ }^{5} \mathrm{O}$ uso do termo "necessariamente presente/ausente" diz respeito à definição de um protótipo de SCN. Ou seja, a presença ou ausência de tais construções são necessárias sob um ponto de vista lógico para a definição de um protótipo de SCN. Uma língua é classificada como possuindo um dado SCN se existe nessa língua construções características de um dado sistema. As construções podem ser obrigatórias ou opcionais na língua, abarcando todos os nomes ou apenas uma parte dos nomes dessa língua.

${ }^{6}$ Ainda que os sistemas de classificadores são definidos com base em alvos prototípicos do $\mathrm{SN}$, em muitos desses sistemas os classificadores são também encontrados em mais de um alvo, como por exemplo os classificadores "numerais" do Mandarim, que ocorrem tanto no numeral quanto no demonstrativo (Aikhenvald 2000). 
CHACON \& PRADO SATELES - EXPLORAC̣ÕES SOBRE PADRÕES...

Tabela 3: Critérios para definição de protótipos de SCN

\begin{tabular}{|c|c|c|c|c|c|}
\hline \multirow{2}{*}{ Sistema } & \multicolumn{3}{|c|}{ Distribuição morfossintática } & \multirow{2}{*}{ Semântica } & \multirow{2}{*}{$\begin{array}{l}\text { Número de } \\
\text { categorias }\end{array}$} \\
\hline & Nomes & SN & Predicado & & \\
\hline GÊNERO & opcional & 1 ou mais ambientes & opcional & $\begin{array}{l}\text { - Masculino, feminino } \\
\text { - Humano, não-humano } \\
\text { - Animado, inanimado } \\
\text { - Neutro (ou residual) }\end{array}$ & 2 ou 3 \\
\hline $\mathrm{CN}$ & presente & 1 ou mais ambientes & opcional & \multirow{3}{*}{$\begin{array}{l}\text { - Propriedades físicas } \\
\text { - Utilidade } \\
\text { - Gênero (opcional) }\end{array}$} & \multirow{3}{*}{2 ou mais } \\
\hline CL VERBAIS & ausente & ausente & presente & & \\
\hline OUTROS CL & opcional & 1 ou 2 ambientes & ausente & & \\
\hline
\end{tabular}

\section{Resultados}

\subsection{Número de SCN}

Das 23 línguas analisadas, 22 apresentaram SCN nas relações gramaticais dentro do SN e 20 apresentaram sistemas na relação entre argumentos e predicados. ${ }^{7}$ A tabela 4 resume esses dados, os quais nos permitem visualizar que existe sempre um número maior ou igual de sistemas nas relações gramaticais do SN do que entre argumentos e predicados nas línguas estudadas.

${ }^{7}$ As línguas Kariri (Rodrigues 1997) e Sikuani (Queixalós 1998) possuem um complexo SCN no SN, mas esse não é relativo às relações gramaticais dos argumentos de um predicado. Em Sikuani, apenas verbos nominalizados portam morfemas de classificação nominal. O mesmo vale para o Rikbátsa, onde o sistema de gênero é relevante a predicados não verbais e nominalizações, ainda que a língua possua um sistema à parte de classificadores verbais (Silva 2011). A língua Yurakaré fora inicialmente incluída em nosso corpus pois tanto van Gijn (2006) quanto Birchall (2014) a listaram como possivelmente possuindo um sistema de gênero fusionado com os índices de pessoa e número. Uma releitura do trabalho de van Gijn nos sugere que não há gênero nesta língua, e que a confusão a esse respeito ocorreu devido a um padrão não muito claro na marcação de número nos nomes e verbos. Que a língua não possui um sistema de gênero foi também notado pelo estudo do SN de Krasnoukhova (2016). 
Tabela 4: Distribuição de línguas com $n$ sistemas de classificação nominal nas relações gramaticais entre nomes e constituintes do SN e entre argumentos e predicados

\begin{tabular}{|c|c|c|c|}
\hline $\begin{array}{l}\text { Número de Sistemas } \\
\text { (Número de línguas) }\end{array}$ & No SN & No Predicado & Línguas \\
\hline $\begin{array}{l}\text { Um sistema } \\
\text { (Total } 8 \text { línguas) }\end{array}$ & 1 & 1 & $\begin{array}{l}\text { Chipaya, Lokono, Miraña, Wari, Tehuelche, Kwazá, } \\
\text { Mosetén, Munduruku }\end{array}$ \\
\hline \multirow{3}{*}{$\begin{array}{l}\text { Dois sistemas } \\
\text { (Total } 10 \text { línguas) }\end{array}$} & \multirow{3}{*}{2} & 0 & Sikuani \\
\hline & & 1 & Baniwa, Kubeo, Siona \\
\hline & & 2 & Apurinã, Baure, Jarawara, Movima, Paumari, Saliba \\
\hline \multirow{3}{*}{$\begin{array}{l}\text { Três sistemas } \\
\text { (Total } 3 \text { línguas) }\end{array}$} & \multirow{3}{*}{3} & 0 & Kariri \\
\hline & & 1 & Rikbatsa \\
\hline & & 2 & Tariana \\
\hline $\begin{array}{l}\text { Cinco sistemas } \\
\text { (Total } 1 \text { língua) }\end{array}$ & 5 & 3 & Palikur \\
\hline
\end{tabular}

\subsection{Tipos de SCN}

Entre os tipos de SCN que encontramos nas relações gramaticais entre argumentos e predicados, temos 18 sistemas de gênero, 9 sistemas de $\mathrm{CN}$ e apenas 2 sistemas de classificadores verbais. Em nossa definição (seção 3), classificadores verbais são os únicos que não ocorrem no $\mathrm{SN}$, mas, como as línguas que apresentam classificadores verbais (Palikur e Rikbatsa) também apresentam outros SCN no SN, é possível fazermos as seguintes generalizações:

- Generalização 1: sempre que uma língua tiver um SCN no predicado ela também terá um sistema no $\mathrm{SN}^{8}$

- Generalização 2: Todos os SCN encontrados no predicado também ocorrem no SN (excetuando-se os classificadores verbais, por definição).

Essas generalizações são importantes sob um ponto de vista tipológico pois apontam para uma relação de implicação SN > Predicado, no sentido de que a classificação nominal no SN é mais comum e toma precedência à classificação no predicado. Sob um ponto de vista diacrônico, como iremos abordar na seção 5.2, isso também aponta que os SCN que indexam argumentos verbais possuem sua origem no SN.

\subsection{Tipos de SCN e relações gramaticais de argumentos}

Entre os 18 sistemas de gêneros que indexam argumentos verbais, vemos que 16 indexam gênero do argumento $\mathrm{A}$, enquanto 14 indexam o gênero do argumento $\mathrm{O}$. $\mathrm{O}$

${ }^{8}$ Essa generalização também parece se sustentar num contexto global, havendo apenas uma exceção identificada até agora pela língua Berik (uma língua não-Austronésia falada em Papua Nova Guiné). Nessa língua, verbos classificam os argumentos na função de objeto em gênero, porém gênero não é expresso em nenhum outro contexto morfossintático (Westrum 1988). Agradeço a Dan Ke por haver me fornecido essa informação (comunicação pessoal em maio de 2019). 
CHACON \& PRADO SATELES - EXPLORAÇÕES SOBRE PADRÕES... padrão de indexação dos argumentos pode ainda ser subdividido de acordo como os padrões de alinhamentos, conforme a tabela 5 .

Tabela 5: Alinhamentos em sistemas de gênero

\begin{tabular}{|l|l|l|}
\hline \multicolumn{2}{|l|}{ Alinhamentos } & Total numérico e Línguas \\
\hline Nominativo & A/S & 4 - Chipaya, Kubeo, Palikur, Siona \\
\hline Nominativo-Acusativo & A/S vs. O & 1 - Mosetén \\
\hline Acusativo & O & 1 - Wari' \\
\hline Direto & A/S/O & 4 - Jarawara (2 sistemas), Movima, Paumari, Wari \\
\hline Ativo-Estativo & A/Sa vs. O/So & 7 - Apurinã, Baniwa, Baure, Lokono, Palikur, Saliba, Tariana \\
\hline Estativo & O/So & 1 - Tehuelche \\
\hline
\end{tabular}

Há línguas em que gênero indexa apenas os argumentos $\mathrm{A} / \mathrm{S}$, como em Kubeo exemplificado em (1). Outras línguas indexam por paradigmas distintos $\mathrm{A} / \mathrm{Sa}$ e $\mathrm{O} / \mathrm{So}$, como o Baniwa exemplificado em (2). Wari' é um caso singular por indexar apenas o argumento $\mathrm{O}$, como em (3). Já Tehuelche codifica o argumento estativo $\mathrm{O} /$ So em gênero como será ilustrado na seção $5.1 .^{9}$

(1) Kubeo (dados dos autores)
a. maria eda-biko
maria chegar-3F
'a Maria chegou'
b. maria take-de hã-miko
maria macaco-N.NOM ver-3F
'a Maria viu o macaco'

(2) Baniwa (Ramirez 2001: 110)

a. li-heeko-ka-wa

3NFA/SA-correr-SUB-MED

'ele está correndo'

b. iinona-ka-ni

triste-SUB-3NFO/So

'ele está triste'

c. li-iiñha-ka-ni

3NFA/SA-comer-SUB-3NFO/So

'ele o está comendo'

${ }^{9}$ Abreviaturas dos exemplos (1) a (3) em ordem alfabética: 3 '3a pessoa', f 'feminino'; med; n.nom 'nãio nominativo', nfA/SA 'não feminino argumento $\mathrm{A}$ e Sa'; nfO/So 'não feminino argumento O e So'; perf 'perfectivo'; sg 'singular'; sub 'subordinador, progressivo'. 
(3) Wari' (Apontes 2015: 18-190)
a. momaw na trama
correr.PL 3SG homem
'o homem fugiu'

$\begin{array}{cllll}\text { b. krik } & \text { pin } & \text { na-am } & \text { narima? } & \text { trama } \\ \text { ver } & \text { PERF } & \text { 3sG-3.SG.F } & \text { mulher } & \text { homem }\end{array}$

'o homem viu a mulher'

$\begin{array}{llll}\text { c. krik pin na-am } & \text { trama } & \text { narima? } \\ \text { ver PERF } & \text { 3SG-3.SG.F } & \text { homem } & \text { mulher } \\ \text { 'a mulher viu o homem' } & & \end{array}$

Conforme esperado tipologicamente, os sistemas de classificadores verbais apenas classificam os argumentos $\mathrm{S} / \mathrm{O}$. Já para os sistemas de $\mathrm{CN}$, observamos uma maior tendência à expressão dos argumentos $\mathrm{S} / \mathrm{O}$, com 8 casos em 9 , enquanto $\mathrm{A} / \mathrm{S}$ teve apenas 1 caso encontrado em Miraña (ver seção 5.2). Isso vem confirmar a observação de Krasnoukhova (2012) mencionada no ponto (3) da seção 2.3. Um outro caso interessante é o da língua Sáliba, em que as classes nominais são usadas para indexar o argumento $\mathrm{T}$ de verbos ditransitivos, i.e., o argumento paciente e não recipiente, este último sendo indexado somente pelo sistema de gênero (ver seção 5.2).

As línguas que possuem dois sistemas de gênero no predicado (Palikur e Jarawara) usam o mesmo sistema de alinhamento para ambos. Já línguas com um sistema de gênero e outro de $\mathrm{CN}$ ou classificadores verbais possuem um padrão de distribuição complementar: gênero indexa $\mathrm{A} / \mathrm{S}$ enquanto $\mathrm{CN}$ indexa $\mathrm{S} / \mathrm{O}$.

Com base nessas observações, podemos oferecer a seguinte generalização:

Generalização 3: existe uma leve tendência para sistemas de gênero indexarem o argumento $\mathrm{A}$, enquanto $\mathrm{CN}$ ou classificadores verbais possuem uma forte tendência para indexar o argumento $\mathrm{O}$. Nenhum sistema indexa apenas $\mathrm{S}$.

\subsection{Pessoa e número}

Todos os SCN classificam os argumentos em terceira pessoa. Apenas o Kubeo, em um de seus paradigmas, classifica tanto a primeira quanto a terceira pessoa em gênero. Isso ocorre, provavelmente, porque as formas de $1^{\text {a }}$ pessoa do paradigma de passadodistante se desenvolveram a partir de formas verbais não-finitas, em que a distinção de gênero é feita para qualquer pessoa do discurso (Chacon 2012: 299-300; ver também Chacon e Michael 2018). Os dois paradigmas de pessoa-gênero-número do Kubeo estão representados na tabela 6 abaixo: 
CHACON \& PRADO SATELES - EXPLORAÇÕES SOBRE PADRÕES...

Tabela 6: indexadores verbais de pessoa-gênero-número em Kubeo

\begin{tabular}{|l|c|c|}
\hline & Passado Recente & Passado Distante \\
\hline 3 masculino singular & -bi & -ame \\
\hline 3 feminino singular & -biko & -ako \\
\hline 3 animado plural & -ma & -ima \\
\hline 2 pessoa & -wi & -ãwi \\
\hline 1 inclusivo & & \\
\hline 1 exclusivo & \multirow{2}{*}{} & -karã \\
\hline 1 masculino singular & & -kaki \\
\hline 1 feminino singular & & -kako \\
& & \\
\end{tabular}

Já as línguas Jarawara, Miraña, Mosetén e o sistema de CN do Tariana classificam qualquer pessoa do discurso. Não há aparentemente uma tendência diferente para os tipos distintos de SCN. Com base nesses dados, temos a seguinte generalização:

Generalização 4: $3>1>2$ : a classificação de argumentos se faz primariamente para argumentos na $3^{\mathrm{a}}$ pessoa, seguido por argumentos na $1^{\mathrm{a}}$ pessoa e só então para a $2^{\mathrm{a}}$ pessoa.

Para as línguas cujas fontes precisaram informações sobre a relação entre número e padrões de indexação, observamos que $10 \mathrm{SCN}$ classificam tanto argumentos singulares quanto não-singulares (dual, paucal ou plural, a depender do sistema de número); 12 SCN apenas classificam argumentos singulares; enquanto apenas um sistema, o que opõe animados vs. inanimado na língua Jarawara, classifica apenas os argumentos nãosingulares (ver seção 5.1). Entre os sistemas de gênero, 5 classificam tanto argumentos singulares quanto plurais e 13 classificam apenas um argumento singular. Entre os onze sistemas de classificadores verbais e $\mathrm{CN}$, em nenhum foi reportado uma restrição com relação a número.

É interessante notar que em línguas com mais de um sistema, número faz parte do paradigma de expressão de gênero, mas não do de classificadores verbais ou $\mathrm{CN}$ com em Sáliba e Apurinã. Em outros casos de $\mathrm{CN}$, número pode ser expresso por índices pessoais, mas não pelos morfemas $\mathrm{CN}$ como em Mundurukú e Kwazá. ${ }^{10}$ Com base nessas considerações, temos a seguinte generalização:

Generalização 5: sistemas de gênero apresentam uma maior tendência a restringir a classificação a argumentos singulares do que sistemas de CN e classificadores verbais.

O universal 32 de Greenberg prevê que quando um verbo concorda com o sujeito ou objeto em gênero, ele também concorda em número. Isso se provou verdadeiro em nosso levantamento se assumirmos um ponto de vista amplo, i.e., que em todas as línguas com SCN de argumentos há alguma forma de indexar o número de argumentos. Porém, sob um "ponto de vista estreito", existem alguns problemas que merecem estudos futuros mais

${ }^{10}$ É bem verdade que para 6 dos 11 sistemas de classificadores verbais e $\mathrm{CN}$ não obtivemos uma informação explícita nas fontes consultadas sobre se haveria ou não restrição de número. 
detalhados. Por exemplo, em Palikur há expressão de número singular e plural para $1^{\mathrm{a}}$ e $2^{\mathrm{a}}$ pessoa nos verbos, porém não para a $3^{\text {a }}$ pessoa - sendo que gênero apenas classifica a $3^{\text {a }}$ pessoa (Aikhenvald e Green 1998: 437).

\subsection{SCN no predicado e no SN}

Vamos agora abordar as correlações entre os padrões de expressão dos SCN em predicados e no SN. Não trataremos dos sistemas de classificadores verbais, pois esses, por definição, não possuem expressão no SN. Também não trataremos dos demais sistemas de classificadores, pois estes não possuem expressão no predicado.

\subsubsection{Formas pronominais livres e demonstrativos}

Vamos considerar conjuntamente os pronomes livres (ou enfáticos) e os demonstrativos como construções dêiticas que classificam seus referentes e potencialmente podem ser usados com referência anafórica a correferentes nominais. ${ }^{11}$ Dos 18 sistemas de gênero que indexam os argumentos de um predicado, apenas o sistema de masculino vs. feminino em Jarawara não possui um contraste de gênero nas formas pronominais livres, enquanto o sistema que contrasta animado vs. inanimado ocorre de modo marginal. Por exemplo, os chamados "pronomes cardinais" por Dixon (2004: 378) ocorrem como um SN autônomo em certas posições sintáticas como complementos de cópulas. Não há distinção de gênero para a $1^{\text {a }}$ ou a $2^{\text {a }}$ pessoa (e.g. owa ' $1^{\text {a }}$ pessoa singular', tiwa ' $2^{\text {a }}$ pessoa singular'). A $3^{\text {a }}$ pessoa singular não admite o uso de pronomes (um nome deve ser usado nessa posição); apenas a $3^{\text {a }}$ pessoa não-singular animado possui uma forma pronominal nesta posição (e.g. mee ' 3 a não-singular animado').

Já com relação aos demonstrativos, 4 sistemas de gênero não são expressos por essa classe de palavras como em Jarawara, Mosetén, Sáliba e Palikur. Em todas essas línguas, com exceção do Mosetén, um outro sistema de gênero ou CN classifica um nome correferente junto aos demonstrativos. Em Palikur os demonstrativos contrastam masculino vs. feminino vs. neutro, mas o sistema de feminino vs. não-feminino não é expresso nessa classe de palavras (ver discussão em 5.1). Em Jarawara, os demonstrativos proximais que ocorrem em SN antes de predicados contrastam gênero feminino vs. masculino haaha 'esta' haahi 'este', respectivamente, porém não há contraste entre os gêneros animado vs. inanimado.

Já com relação aos 9 sistemas de $\mathrm{CN}$ com indexadores no predicado, apenas 3 possuem marcação em formas pronominais (Miraña, Mundurukú e Tariana), enquanto

${ }^{11}$ Uma vez que há detalhes em cada língua que podem nos escapar neste tipo de trabalho tipológico, resolvemos nos ater às fontes em sua análise sobre o que são formas pronominais e demonstrativas, mas também incluímos no que aqui tratamos como "pronomes livres" quaisquer pro-formas morfossintaticamente independentes e usadas anaforicamente, mesmo se as fontes não diretamente as analisaram como pronomes. Dois casos ilustrativos são o Tariana e o Mundurukú. Em Tariana, Aikhenvald (2003: 108) descreve o uso de "artigos especificadores" combinados com classificadores para se fazer uma referência anafórica. Em Mundurukú, nomes em função classificadora (tratados aqui como 'CN') podem se combinar com demonstrativos (Gomes 2009) ou com o chamado morfema relacional de "não-contiguidade", quando então possuem uma referência anafórica. 
CHACON \& PRADO SATELES - EXPLORAÇÕES SOBRE PADRÕES... a metade dos sistemas de $\mathrm{CN}$ se combina com demonstrativos. A tabela 7 resume a distribuição dos sistemas conforme sua marcação ou não junto a formas pronominais livres e demonstrativos.

Tabela 7: Gênero e CN em demonstrativos e formas pronominais livres

\begin{tabular}{|l|l|l|l|l|}
\hline & $\begin{array}{l}\text { Demonstrativos \& } \\
\text { Pronomes }\end{array}$ & $\begin{array}{l}\text { Demonstrativos } \\
\text { apenas }\end{array}$ & $\begin{array}{l}\text { Pronomes } \\
\text { apenas }\end{array}$ & $\begin{array}{l}\text { Nem Demonstrativos } \\
\text { Nem Pronomes }\end{array}$ \\
\hline Gênero & $\begin{array}{l}\text { Apurinã, Baniwa, } \\
\text { Baure, Chipaya, Kubeo, } \\
\text { Lokono, Movima, } \\
\text { Palikur, Paumari, Siona, } \\
\text { Tehuelche, Wari }\end{array}$ & Jarawara & $\begin{array}{l}\text { Jarawara, } \\
\text { Mosetén, } \\
\text { Saliba, Tariana }\end{array}$ & \\
\hline CN & $\begin{array}{l}\text { Miraña, Munduruku, } \\
\text { Tariana }\end{array}$ & Sáliba, Kwazá & & \\
\hline
\end{tabular}

Como se observa na tabela 6 , existe uma maior tendência aos sistemas de gênero que indexam argumentos verbais a serem encontrados junto a pronomes e demonstrativos do que os sistemas de CN. A única exceção seria a do sistema de gênero que opõe feminino vs. não-feminino em Palikur, mas como veremos na seção 5, este sistema é, na verdade, subordinado ao sistema de gênero que opõe feminino vs. masculino vs. neutro, o qual por sua vez é encontrado junto a demonstrativos e pronomes. Isso nos possibilita a seguinte generalização:

Generalização 6: sistemas de gêneros que indexam argumentos de um predicado também indexam referentes de pronomes e/ou demonstrativos

\subsubsection{Construções possessivas}

Nossa base de dados divide as construções possessivas entre as que indexam o possuidor e as que indexam o nome possuído. Entre os sistemas que classificam o possuidor, encontramos 13 dos 18 sistemas de gênero. ${ }^{12}$ Vejamos, por exemplo, as formas do Apurinã $u$-kuwu 'cabeça dele' e $o-k u w u$ 'cabeça dela' (Facundes 2000: 380).

Em Paumari tanto o sistema de gênero quanto o de CN podem aparecer como sufixos em um nome inalienável possuído e indexando o nome possuidor (Aikhenvald 2010: 239). Vejamos o exemplo (4) que ilustra a marcação de gênero: -ø para 'masculino' e -ni para 'feminino'.

(4) Paumari (Aikhenvald 2010: 239) $)^{13}$
a. kahami
dama- $\varnothing$
palmeira(M) pé(F)-M
'pé de uma espécie de palmeira'

${ }^{12}$ Foram excluídas dessa contagem línguas que não possuem um tipo de construção possessiva específica diferente da justaposição de nomes ou pronomes.

${ }^{13}$ Abreviaturas para a língua Paumari: CN.ka- 'classe nominal prefixo ka-'; F 'feminino'. 


\section{b. ava vadi-ni \\ árvore $(\mathrm{F})$ galho(F)-F \\ 'galho de uma árvore'}

Ambos os nomes possuidores em (4) pertencem à $\mathrm{CN}$ denominada de 'não- $k a$ ', i.e., são nomes que não controlam a indexação pelo prefixo $k a$ - em um outro constituinte sintático. Quando o possuidor pertence à $\mathrm{CN} k a$, tanto gênero quanto $\mathrm{CN}$ são indexados no nome possuído, conforme ilustramos em (5)

(5) Paumari (Aikhenvald 2010: 240)

$\begin{array}{ll}\text { kaira } & \text { ka-bono-ni } \\ \text { goiaba(F/CN.ka) } & \text { CN.ka-fruta-F } \\ \text { 'fruta da goiaba' } & \end{array}$

De fato, Paumari é excepcional pois é única língua com CN que classifica o possuidor. Seu sistema de CN é problemático por diferentes razões, conforme voltaremos a discuti-lo na seção 5.2 .

Foram encontrados apenas 8 sistemas que indexam o nome possuído, dos quais 6 são de CN (Baniwa, Kwazá, Sáliba, Mundurukú, Miraña e Tariana) e 2 de gênero (Kubeo e Mosetén). As línguas Kubeo e Baniwa foram incluídas nessa contagem com a ressalva de que apenas usam $\mathrm{CN}$ em pronomes possessivos, mas não em construções possessivas adnominais. Vejamos os exemplos do Kubeo abaixo, em que a marca de posse adnominal não indexa o gênero do possuidor nem do nome possuído, mas o pronome possessivo indexa a pessoa do possuidor e o gênero do nome possuído:

(6) Kubeo (fonte dos autores)
a. Peduro-i yawimi
POSSESSÃO ADNOMINAL
Pedro-Pos cachorro
'o cachorro de Pedro'
b. Peduro hi-ki PRONOME POSSESSIVO
Pedro 3.Pos-M
'o ser masculino de Pedro (parente, cachorro, etc.)

Alguns sistemas não classificam nem o possuidor nem o nome possuído: os sistemas de $\mathrm{CN}$ em Apurinã, Baure e Movima (essas línguas classificam o possuidor por um sistema de gênero), e os sistemas de gênero em Siona e Jarawara - esse último classifica o possuidor com base num segundo sistema de gênero: animado vs. inanimado.

Com base no papel de gênero e CN na classificação dos nomes em construções possessivas, podemos oferecer as seguintes generalizações (ver também ponto [1] abordado por Krasnoukhova [2012] e apresentado na seção 2.3):

Generalização 7: sistemas de gêneros que indexam argumentos de um predicado possuem uma forte tendência a também indexarem o possuidor em vez do possuído 
Generalização 8: sistemas de CN que indexam argumentos de um predicado possuem uma forte tendência a também indexarem o possuído em vez do possuidor

\subsubsection{Adjetivos e numerais}

Neste trabalho estamos usando o termo "adjetivo" num sentido amplo, como um lexema que descreve qualidades ou propriedades de um referente nominal usado como modificador no SN, sem necessariamente implicar que as línguas tenham uma classe morfológica de adjetivos, ou se a modificação de um referente nominal é na verdade feita por outras classes de palavras.

Segundo o universal 31 de Greenberg (ver seção 2.4), se um verbo concorda com o sujeito ou objeto em gênero, então o adjetivo também sempre concorda com o nome em gênero. De fato, todas as línguas em nosso corpus em que o argumento é classificado por um padrão de indexação argumental no predicado possuem um sistema de indexação do referente nominal no adjetivo. Assim, esse universal é mantido como absoluto em nosso contexto se tomamos um ponto de vista amplo que agregue gênero e CN.

Porém, parece haver uma assimetria entre os sistemas de gênero e CN. Entre os 18 sistemas de gênero que indexam argumentos de um predicado, encontramos 11 que também indexam um referente modificado por um adjetivo. Entre os 7 sistemas de gênero ausentes no adjetivo, as respectivas línguas possuem um outro sistema de gênero (Jarawara e Palikur) ou de CN (Baniwa, Baure, Movima, Sáliba e Tariana) que suplanta essa ausência. Já entre os 9 sistemas de CN, 8 são encontrados junto a adjetivos, a exceção sendo Apurinã, em que adjetivos são indexados pelo sistema de gênero.

Com relação aos numerais, 11 dos 18 sistemas de gênero não são usados junto a modificadores numerais. Vemos assim que há uma ligeira tendência para que gênero seja mais usado com adjetivos do que com numerais. Já com sistemas de CN, 8 dos 9 sistemas de CN são usados com numerais. A língua Apurinã novamente é a exceção, pois usa gênero com numerais e adjetivos.

Tomando como base essa assimetria, podemos elaborar a seguinte generalização

Generalização 9: Sistemas de CN possuem uma tendência maior do que sistemas de gênero a classificar um referente nominal em construções com adjetivos e numerais

Além disso, esses dados sugerem que para o universal 31 de Greenberg ser mantido, devemos reconhecer um padrão de complementariedade entre dois SCN numa mesma língua.

\subsubsection{Nome}

Na seção 3, a definição de gênero postula que a presença de morfemas classificadores junto aos nomes é opcional, não necessariamente ocorrendo para todos os sistemas. Por outro lado, a ocorrência de morfemas de $\mathrm{CN}$ junto a nomes foi tida como obrigatória ao menos para um conjunto de nomes. 
$\mathrm{O}$ uso de gênero ou $\mathrm{CN}$ na derivação ou flexão nominal foi observado em 17 dos 28 sistemas que indexam argumentos verbais. Em 10 dos 18 sistemas de gênero não há morfemas classificadores morfologicamente combinados a uma base nominal, enquanto apenas 1 dos 9 sistemas de CN não classifica os nomes morfologicamente. Esse é o caso do sistema de $\mathrm{CN}$ da língua Paumari, que é excepcional por outras razões (ver seção 5.2). Isso nos permite a seguinte generalização:

Generalização 10: Sistemas de CN possuem uma maior tendência do que sistemas de gênero a apresentar morfemas classificadores junto a um lexema nominal

\section{Discussão}

Das 10 generalizações que chegamos com a análise dos dados na seção 4, sete sugerem uma distinção tipológico-funcional entre sistemas de gênero e CN (generalizações 3, 5, 6, 7, 8, 9 e 10), enquanto outras três são neutras com relação a essa distinção (generalizações 1 , 2 e 4). Além disso, os sistemas de classificadores (verbais, genitivais, etc.) se comportaram conforme esperado pelas definições que adotamos. Isso sugere que os critérios utilizados para definir os tipos de sistemas (seção 3) se provaram úteis para explicar os padrões encontrados nos dados.

Tomando as generalizações como base, podemos complementar a tabela 3 e propor um conjunto de propriedades contrastivas que tendem a definir os protótipos de gênero e CN com relação aos parâmetros semânticos e morfossintáticos observados na indexação dos argumentos verbais e constituintes do SN. Essas propriedades estão expressas na tabela 8 .

Tabela 8: Propriedades tipológicas contrastivas entre sistemas prototípicos de $\mathrm{CN}$ e gênero ${ }^{14}$

\begin{tabular}{|l|l|l|}
\hline & CN & Gênero \\
\hline Constituintes no SN & $\begin{array}{l}\text { 1 Nome }>\text { Modificador } \\
\text { 2 Adjetivos / Numerais }>\text { Pronomes } \\
\text { Demonstrativos }\end{array}$ & $\begin{array}{l}\text { 1 Modificador }>\text { Nome } \\
2 \text { Pronomes / Demonstrativos }> \\
\text { Adjetivos / Numerais }\end{array}$ \\
\hline Macro-papéis dos argumentos & O $>$ A & A $>$ O \\
\hline Possessão & Possuído > Possuidor & Possuidor > Possuído \\
\hline Número & sg/pl & sg $>$ pl \\
\hline Categorias semânticas & Forma física & Animacidade / sexo \\
\hline Número de categorias & 6 ou mais & Até 3 \\
\hline
\end{tabular}

Existem, no entanto, casos de sistemas que não se alinham a algumas das propriedades listadas. São casos de sistemas de gênero e CN menos prototípicos e/ou onde encontramos a coexistência de mais de um sistema em distribuição complementar ou sistemas

${ }^{14} \mathrm{O}$ símbolo ">" indica relação hierárquica entre padrões possíveis, como "A > O" que deve ser lido como "A tem uma maior tendência do que O a ser indexado" em tal sistema. O símbolo "/ indica uma relação não hierárquica; por exemplo, "Adjetivos / Numerais > Pronomes / Demonstrativos" deve ser lido como "tanto adjetivos quanto numerais possuem uma maior tendência a indexarem o núcleo do SN do que pronomes ou demonstrativos. 


\section{CHACON \& PRADO SATELES - EXPLORAC̄õES SOBRE PADRÕES...}

sobrepostos. Esses casos serão discutidos na seção 5.1 e 5.2. Na seção 5.3 vamos discutir alguns pontos que podem servir de explicações tipológico-funcionais para os resultados deste estudo.

\subsection{Sistemas de Gênero}

Dos 18 sistemas que analisamos, temos poucas exceções com relação aos parâmetros apresentados pela tabela 8 e 3 (seção 3). Nas relações gramaticais, apenas Wari' e Tehuelche não indexam o argumento A. Wari' indexa apenas o argumento O (Apontes 2015: 192). Em Tehuelche, os verbos que marcam o gênero de seus argumentos são verbos intransitivos que atribuem uma propriedade ao seu único argumento (So) (Garay 1998: 261), conforme em (7a) e (7b) abaixo, e certos verbos transitivos que marcam o gênero dos objetos (O) conforme (8a) e (8b) (Garay 1998: 264-6). A oposição de feminino vs. masculino vs. neutro nos nomes em Tehuelche se neutraliza em neutro vs. masc/fem. nos verbos. Notemos como (7a) e (7b) mostram que a expressão nominal do argumento é possível, mas não é obrigatória.

\section{Tehuelche (Garay 1998) ${ }^{15}$}

(7) a. k-aster-s-k'e wajenK

M/F-ser.profundo-E.P.-M.R poço

'O poço é profundo'

b. P-a:r-s- k'n te:m

N-ser.seco-E.P- M.R. terra

'A terra está seca'

(8) a. e-k-erno-s-koT

$1+3 \mathrm{M}+$ deixar+ E.P.+T.F.M

'eu vou deixá-lo'
b. e-xa:t'en ?-erno-s-k'
$1+$ comida $3+$ deixar + E.P. + M.R.
'A comida, eu a deixei'

No SN, existem seis sistemas de gênero que desviam um pouco do protótipo (Mosetén, Kubeo, Siona, Jarawara e Palikur). Cinco sistemas de gênero não indexam o possuidor. Em Siona não há uma construção possessiva específica (Wheeler 1987), em Mosetén e Kubeo indexa-se o nome possuído. Palikur e Jarawara possuem mais de um sistema de gênero que a princípio estão em distribuição sintática aquém dos parâmetros da tabela 8. Em Palikur, ainda que se sobreponham no verbo, semanticamente o sistema (1) feminino vs. não-feminino está incluso no sistema (2) feminino vs. masculino vs. neutro.

${ }^{15}$ Abreviaturas do Tehuelche (Garay 1998: 21): E.P 'especificador do predicado', M/F ‘masculino ou feminino', N 'neutro', 1/2/3 'pessoa', , M.R 'modo real', T.F.M 'tempo futuro imediato'. 
O sistema (1) não se encontra no SN, apenas (2). Porém, faz sentido sob um ponto de vista semântico e morfossintático analisar que (1) e (2) se relacionam como um único sistema ainda que com diferentes alvos (ver discussão em Fedden e Corbett 2017 sobre análises de um versus múltiplos $\mathrm{SCN}$ ).

Jarawara ilustra outra situação. Há dois sistemas de gênero: (1) animado vs. inanimado que classifica o possuidor, o sistema de pronomes livres e argumentos verbais, e (2) masculino vs. feminino que ocorre junto a adjetivos, demonstrativos e verbos. Os verbos em Jarawara possuem três posições onde podemos encontrar um dos sistemas de gênero:

1. animado versus inanimado: índices pessoais pré-verbais

2. masculino vs. feminino:

a) sufixo verbal -rawa 'feminino plural'

b) sufixos de modo verbal fusionados com gênero

Os sufixos de modo verbal são obrigatórios (Dixon 2004: 418). O argumento indexado pode estar em função de $\mathrm{S}$, como em (9), e ou A ou $\mathrm{O}$ em construções transitivas, conforme demonstrado em (10a) e (10b), respectivamente:

(9) Jarawara (Dixon 2004) ${ }^{16}$
a. Miotos ki-joma-ke-ka
Mioto(m) movimento-PASSAGEM-vindo-DECL.MSC
'O Mioto entrou'

b. Watatis ki-joma-ke-ke

Watati(f) movimento-PASSAGEM-vindo-DECL.FEM

'A Watati entrou'
(10) a. Mioto Watati awa-ka
$\operatorname{Mioto}(\mathrm{m}) \quad$ Watati(f) ver-DECL.M
'(O Mioto) viu a Watati'
b. Watati Mioto hi-wa hi-ke
Watati(f) Mioto(m) OC-ver OC-DECL.FEM
'O Mioto viu (a Watati)'

A distinção animado vs. inanimado ocorre somente na $3^{a}$ pessoa não-singular por meio dos índices pessoais mera codificando $\mathrm{O}$ e mee codificando $\mathrm{A} / \mathrm{S} / \mathrm{O}$ de argumentos animados. Quando estes índices estão presentes, assim como qualquer outro índice pessoal, neutraliza-se o gênero nos sufixos de modo, que passam a se flexionar em feminino por padrão. A oração abaixo ilustra o uso dessas formas:

\footnotetext{
${ }^{16}$ Abreviaturas para o Jarawara (adaptado de Dixon 2004): DECL 'declarativo', M/MSC 'masculino', F/FEM 'feminino', 3 'terceira pessoa', NsG 'não-singular', OC 'construção O [quando o objeto é o tópico]'. 


\section{CHACON \& PRADO SATELES - EXPLORAC̄õES SOBRE PADRÕES...}

(11) Jarawawa (Dixon 2004: 183)

$\begin{array}{lllll}\text { abao } & \text { Jara } & \text { mee } & \text { mee } & \text { kaba-ke } \\ \text { matrinxã }(m) & \text { Branco(m) } & 3 n s g O & \text { 3nsgA } & \text { comr-DECL.FEM }\end{array}$

'os Brancos comem muito matrinxã'

Os falantes de Jarawara podem, no entanto, marcar a pluralidade do argumento e expressá-lo como feminino pelo sufixo -rawa 'feminino plural'. Esse sufixo indexa um argumento feminino não-singular, seja ele animado ou não-animado, em função $\mathrm{A}, \mathrm{O}$ ou S. Ainda que morfológica e semanticamente independente às formas pessoais pré-verbais, quando -rawa 'feminino não-singular' está presente, a forma pessoal deve ser omitida e o gênero do modo declarativo permanece como "feminino", como nos exemplo abaixo:

(12) Jarawara (Dixon 2004: 183)

a. mee.fanawiris (*mee) kobo na-rawa-ke mulheer(f) (3nsgS) chegar Aux-F.NSG-DECL.FEM

'as mulheres chegaram'
b. sirabao Jara (*mee) mee kaba-rawa-ke
cangati(f) Branco(m) (3nsgO) 3nsgA comer-F.NSG-DECL.FEM
'os Brancos comeram um monte de cangati'

Logo, observamos um sistema de dois gêneros, com distribuição complementar no SN e em competição no predicado. Apesar de existirem diferentes posições no predicado, apenas um dos gêneros se manifesta de fato para cada argumento, os falantes tendo tanto razões formais quanto semânticas para ter de escolher ou um ou outro sistema.

Um outro sistema de gênero atípico é encontrado em Chipaya, onde um sistema de gênero é consistente no SN, porém nem verbo nem predicado portam um elemento que indexe o gênero dos seus argumentos. Isso levou Birchall (2016) a tratar sua forma de indexação de argumento como incerta. Cerrón Palomino (2006: 172-5) descreve um conjunto de morfemas chamados de "concordantes" cuja função principal é a de focalizar um dado constituinte da oração declarativa ou interrogativa além de "estabelecer concordância [com base em gênero] entre o elemento que o porta e o participante sujeito da oração". Estes morfemas são opcionais e parecem ser clíticos, pois podem se hospedar tanto no argumento sujeito quanto em "um objeto direto, oblíquo ou qualquer adjunto" que esteja sendo focalizado. Vejamos os exemplos abaixo:

(13) Chipaya (Cerrón Palomino 2006: 174)
$\begin{array}{cll}\text { a. nii } & \text { quta-zh } & \text { oqhtra } \\ \text { ele lago-3.MSC } & \text { vai }\end{array}$
'ele vai ao lago'
b. nii-zh quta oqhtra
ele-3.MSC lago vai
'ele vai ao lago'




$\begin{array}{lll}\text { c. naa } & \text { quta-1 } & \text { oqhtra } \\ \text { ela } & \text { lago-3.FEM } & \text { vai } \\ \text { 'ela vai ao lago' } & \end{array}$

Estes morfemas são sensíveis às relações gramaticais em uma oração e, portanto, são um tipo de construção que seleciona um dos argumentos (A/S) ainda que o constituinte alvo não seja a palavra verbal nem esteja necessariamente no predicado. É, sem dúvida, uma construção suis generis em nosso corpus, mas que ainda assim satisfaz os requisitos tipológicos definidos na seção 2.1.

\subsection{Sistemas de $\mathrm{CN}$}

Dos 9 sistemas de CN com indexação de argumentos em nosso corpus, Kwazá e Mundurukú são os que possuem todas as propriedades da tabela 8. As línguas Baure e Movima se diferenciam dessas apenas por não usarem os CN em construções possessivas. Sáliba e Tariana também se comportam como o protótipo, porém apenas usam o sistema de CN junto a verbos em certos contextos morfossintáticos especiais. Em ambas as línguas, o sistema de gênero sempre está marcado no predicado. Em Sáliba, CN são usadas unicamente com um argumento T, como em (14):

(14) Sáliba (Estrada Ramirez 1996) ${ }^{17}$

$\begin{array}{lllll}\text { hi-xu ãxe } & \text { kai-to } & \text { x-ie-a-to-ã-gido } & \text { ũkudo-di } \\ \text { DEM-F } & \text { ontem } & \text { água-CL } & \text { 3f-dar-CL-REAL-2.PL } & \text { 2.PL-DAT } \\ \text { 'ela deu água para vocês ontem' } & \end{array}$

Já em Tariana, sistemas de gênero e CN podem ser formalmente diferenciados ainda que semanticamente haja sobreposição (e.g. ambos os sistemas classificam certos seres animados em 'feminino'). No predicado, gênero é marcado para os argumentos nucleares por clíticos verbais, enquanto $\mathrm{CN}$ são marcadas no verbo se há um processo de topicalização de um argumento $\mathrm{S} / \mathrm{O}$, conforme ilustrado abaixo:

(15) Tariana (Aikhenvald 2003:283) ${ }^{18}$

$\begin{array}{lll}\text { ha-dapana-ne } & \text { nu-a-ni-dapana-ka } & \text { pi-na } \\ \text { DEM:INAN-CL:HAB-FOC.A/s } & \text { 1sg-give-TOP.ADV-CL:HAB-REC.P.VIS } & \text { 2sg-obj } \\ \text { 'Esta casa (não outra) foi dada por mim para você' } & \end{array}$

Miraña é um caso bem próximo do protótipo, porém os argumentos indexados são $\mathrm{A} / \mathrm{S}$, e nunca $\mathrm{O}$, conforme ilustrado abaixo:

${ }^{17}$ Abreviaturas Sáliba: DEM 'demonstrativo', F 'feminino', CL 'marcador de classe nominal', 2/3 'pessoa', REAL 'modo realis', PL 'plural', DAT 'dativo'.

${ }^{18}$ Abreviaturas Tariana: DEM 'demonstrativo', INAN 'inanimado', CL:HAB 'marcador de classe nominal “Habitação”', FOC 'foco', TOP.ADV ‘avanço de tópico', REC.P.VIS 'passador recente evidencial visual', OBJ 'caso de objeto' 


\title{
CHACON \& PRADO SATELES - EXPLORAC̄õES SOBRE PADRÕES...
}

(16) Miraña (Seifart 2005) ${ }^{19}$

\author{
a. íte-dze (ókahi-ke) \\ ver-FEM anta-ACC \\ 'ela viu (anta)'
b. gwá?dáínu-:bé (ahi)
cortar-MSC esp. de palmeira \\ 'ele corta (a palmeira)'
}

Seifart (2005) analisa um sistema de "marcadores de classes gerais" (Animado [feminino vs. masculino] vs. Inanimado) e "marcadores de classes específicos" (propriedades físicas de nomes inanimados apenas). $\mathrm{O}$ fato de constituírem um único sistema fica claro pelo uso opcional de um marcador de classe geral inanimado ou específico, como em (17).

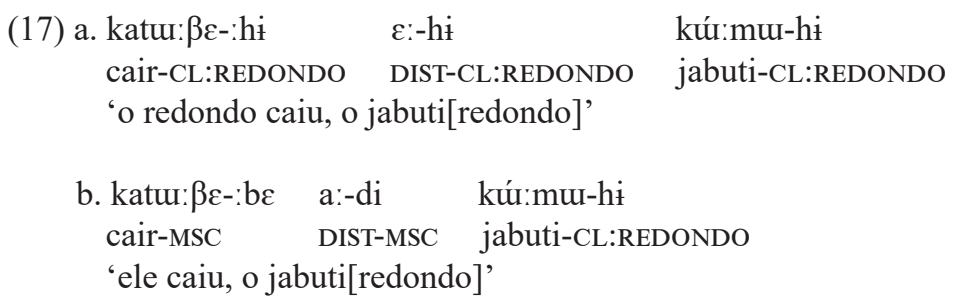

O uso de marcadores de classes específicos nos verbos difere o Miraña de línguas como Kubeo, em que CN não são usadas em predicados verbais, mas apenas gênero. Nessa língua, o sistema de gênero inclui semanticamente o sistema de CN, como em Miraña, porém apenas gênero (ou 'marcadores de classes gerais' nos termos de Seifart 2005) é marcado no predicado. Essa cisão é suficiente para dizer que em Kubeo, CN não ocorre na indexação de argumentos. Vejamos que a topicalização em Tariana está criando um caminho diferente do Miraña ao integrar os sistemas de gênero e CN como sistemas distintos na indexação dos argumentos verbais em contextos como (9) acima.

Os sistemas de $\mathrm{CN}$ mais distantes do protótipo são Apurinã e Paumari. Apurinã é excepcional no sentido que os morfemas de $\mathrm{CN}$ apenas ocorrem junto a nomes e incorporados como classificadores em verbos. Nesse caso, seria um sistema muito semelhante ao de classificadores verbais, porém os classificadores podem ser usados como formativos nominais. Gênero realiza as demais funções do SN e também se encontra em posições morfossintáticas distintas junto a nomes e predicados verbais.

Já a língua Paumari possui uma situação mais complicada, em que gênero e CN são completamente independentes. Paumari é a única língua que tem um sistema de CN que classifica o possuidor em vez do possuído e que não se combina morfologicamente a nomes. Um outro fator menos prototípico é o número de classes em seu sistema de CN: apenas duas (Aikhenvald 2010: 237). Há, no entanto, certas características que o aproximam dos

\footnotetext{
${ }^{19}$ Abreviaturas Miraña: FEM ‘feminino', ACC 'acusativo, MSC 'masculino', DIS ‘demonstrativo distal', CL 'marcador de classe'. 
demais sistemas de $\mathrm{CN}$, como sua marcação de argumentos $\mathrm{S} / \mathrm{O}$ nos verbos, sua ausência em demonstrativos e formas pronominais livres. Segundo nossa interpretação inicial com base nos critérios da seção 3, definimos que a língua Paumari possui um sistema de gênero (masculino vs. feminino) e um sistema de CN com base na classificação dos referentes nominais conforme propriedades físicas, seguindo a mesma interpretação de Aikhenvald (2010). Os dois sistemas são basicamente independentes: semanticamente eles são distintos (2010: 246) e podem ocorrer no mesmo ambiente gramatical, porém ainda possuem posições morfossintáticas distintas, como em adjetivos, construções possessivas e verbos (2010: 237-239).

\subsection{Explicações para as generalizações encontradas}

Seguindo as bases da tipologia diacrônica, regularidades sincrônicas são meramente a consequência de forças diacrônicas (Croft; Denning \& Kemmer 1990). Isso quer dizer que tanto os padrões recorrentes quanto os excepcionais sob um ponto de vista sincrônicotipológico têm como origem fatores que causam ou condicionam mudanças linguísticas em certas direções. Mais recentemente, Cristófaro (2013), ao discutir as bases diacrônicas e sincrônicas da chamada hierarquia de referência (ou animacidade), realça como as hierarquias são válidas como generalizações sincrônicas, mas que no fundo elas são resultados de processos diacrônicos com fontes e caminhos distintos.

Hipotetizamos que os principais mecanismos pelos quais SCN poderiam se gramaticalizar na expressão de argumentos de uma oração são:

(1) gramaticalização de morfemas anafóricos

(2) origem por incorporação nominal

(3) analogia com um sistema de gênero pré-existente

(4) reanálise de predicados não-verbais

Começando pela primeira hipótese, vejamos a hierarquia de concordância pronominal de Givón (2001: 426), que resume tendências observadas em dados diacrônicos e de estudos de corpora textuais com o objetivo de explicar o desenvolvimento de índices pessoais nos predicados verbais. Na base de sua tese está o processo de gramaticalização de formas pronominais anafóricas junto ao predicado e à palavra verbal.

\section{Hierarquia de concordância pronominal (Givón 2001: 426)}

$\begin{array}{lll}\text { Relações Gramaticais } & & \begin{array}{l}\text { Sujeito }>\text { Objeto Direto }>\text { Objeto Indireto } \\ \text { Papel semântico }\end{array} \\ \text { Animacidade } & - & \text { Agente }>\text { Dativo/Benefactivo }>\text { Paciente } \\ \text { Humanidade } & - & \text { Humano }>\text { Inanimado } \\ \text { Topicalização } & - & \text { Topicalizado }>\text { Não-topicalizado }\end{array}$

A semântica dos sistemas que definimos como gênero opera no cerne das hierarquias de animacidade e humanidade na proposta de Givón. Mesmo as distinções feminino e não-feminino/masculino tendem a ser restritas ou semanticamente mais transparentes nos 


\section{CHACON \& PRADO SATELES - EXPLORAC̄̃̃ES SOBRE PADRÕES...}

pontos altos dessas hierarquias semânticas, i.e. entre humanos e certos animais. $\mathrm{O}$ fato de os sistemas de gênero terem um uso recorrente com pronomes livres e demonstrativos explica-se por serem essas classes de palavras as fontes de gramaticalização de marcas de gênero no predicado. ${ }^{20}$ Os mecanismos básicos desse processo são bem conhecidos (Givón 2001: 426; Aikhenvald 2000: 374-9, ver também Chacon e Michael 2018 para uma análise na família Tukáno):

1. topicalização (em geral de participantes altos nas hierarquias de animacidade e pessoa) e expressão anafórica por meio de morfemas dêiticos (pronomes e demonstrativos)

2. morfologização de nomes (e.g. 'mulher', 'pessoa', etc.) junto a bases dêiticas para tornar mais específica a identificação do participante

3. gramaticalização de morfemas dêiticos quando passarem a ocorrer junto a verbos e em posição átona

Por outro lado, as CN tendem a explorar categorias como propriedades físicas, sendo bem mais numerosas e detalhadas as distinções semânticas de objetos inanimados do que animados ou humanos. Isso coloca as CN sempre no lado mais baixo das hierarquias de humanidade e animacidade, e, consequentemente, com menor disposição para assumir papéis temáticos e funções sintáticas de alta hierarquia, além de não se figurarem comumente como tópicos do discurso. É ilustrativo, portanto, que, em Tariana, CN somente ocorrem em construções que promovem a topicalização de um argumento (ver seção 5.2).

Com base nisso, a maneira como as $\mathrm{CN}$ vieram a ser usadas para marcar argumentos de uma oração suscita a reflexão sobre fontes e caminhos diferentes dos seguidos pelos sistemas gênero. Segundo as fontes consultadas, os morfemas que compõem boa parte dos sistemas de CN possuem uma clara etimologia lexical nominal. Sua evolução parece ser bem semelhante ao desenvolvimento de classificadores, i.e. a partir de nomes que passaram a ter uma função nominal formativa e se desenvolveram como termos de classe ou termos genéricos em compostos nominais (De Lancey 1986; Aikhenvald 2000: 354; Croft 2017). Como termos genéricos, esses morfemas formativos passaram a ser também usados anaforicamente. $\mathrm{O}$ fato de muitos dos sistemas de $\mathrm{CN}$ em nosso corpus não serem frequentes com bases pronominais ou demonstrativas sugere que seu uso anafórico se desenvolveu em estruturas "atributivas" como adjetivos e numerais (Givón 2001: 426-30).

Ainda que as etapas e os mecanismos de expansão dos sistemas de $\mathrm{CN}$ dentro do SN merecem um detalhamento futuro, o uso de $\mathrm{CN}$ junto a verbos precisa ser explicado em linhas relativamente independentes. A hipótese de incorporação nominal pode explicar a recorrência de $\mathrm{CN}$ marcando argumentos $\mathrm{S} / \mathrm{O}$; isso sugere que a marcação de $\mathrm{CN}$ no predicado teve uma origem similar a dos classificadores verbais (Mithun 1984). No entanto, é importante ressaltar que nas línguas sul-americanas que analisamos existe um nítido contraste entre sistemas de classificadores verbais (como Palikur e Rikbatas) e sistemas de $\mathrm{CN}$, que são incorporadas ao verbo, usados como índices de anáfora ou concordância no SN e como formativos nominais. $\mathrm{O}$ fato de Apurinã usar as $\mathrm{CN}$ apenas como formativos

${ }^{20}$ Não é algo tão surpreendente se pensarmos que 7 das línguas em nosso corpus são da família Aruák, onde esse padrão é bem recorrente. Mas vejamos que isso também ocorre em línguas de outras famílias. 
nominais e morfemas anafóricos incorporados a verbos sugere que esta língua ocupa uma posição intermediária entre um sistema de $\mathrm{CN}$ e de classificadores verbais.

Já em Miraña, a marcação do argumento $\mathrm{A} / \mathrm{S}$ se assemelha à dos sistemas de gênero, fato curioso se pensarmos que o sistema de "marcadores de classes gerais" de Seifart (2005) poderia ter sido um sistema de gênero independente no passado (ver seção 5.2). Se esse for o caso, podemos supor que o sistema de CN (ou "marcadores de classe específicas") se desenvolveu por analogia ao sistema de gênero, i.e., ocupando as mesmas posições sintáticas onde antes havia apenas gênero.

A terceira possibilidade de evolução SCN junto a verbos é a partir do uso desses morfemas em nominalizações. Na literatura consultada, encontramos tanto sistemas de gênero quanto de $\mathrm{CN}$ com funções associadas à nominalização. Por exemplo, em Rikbatsa gênero feminino vs. não-feminino ocorre em diversos constituintes do SN e ainda como nominalizadores verbais (mas não em predicados finitos). $\mathrm{O}$ mesmo ocorre com $\mathrm{CN}$ em Kubeo e Baniwa. Conforme amplamente documentado, processos de reanálise de nominalizações em predicados verbais finitos são bastante comuns e essa pode ser uma fonte adicional do desenvolvimento de dois tipos de sistemas como indexadores de argumentos.

Em resumo, ainda que haja convergências e possíveis caminhos comuns entres $\mathrm{CN}$ e gênero, parece que as diferenças que servem para estabelecer os protótipos podem ser explicadas por origens e caminhos diacrônicos distintos:

1. CN: fonte em compostos nominais e gramaticalização como índices anafóricos em adjetivos, numerais ou incorporados ao predicado.

2. Gênero: fonte em demonstrativos e pronomes e gramaticalização desses morfemas junto ao predicado.

Em sua origem, compostos nominais versus morfemas anafóricos implicam em funções distintas no uso da marca de $\mathrm{CN}$ ou gênero, respectivamente, gerando padrões de usos distintos, inclusive na seleção de categorias semânticas distintas. Diacronicamente, isso se acumula em mudanças que geram os padrões sincrônicos que observamos e que apontam tendências tipológicas diversas para os sistemas de gênero e $\mathrm{CN}$.

\section{Conclusão}

Analisamos neste trabalho $42 \mathrm{sCN}$, distribuídos em 23 línguas da América do Sul. Ao todo foram identificados $29 \mathrm{sCN}$ que indexam um argumento da oração: dois de classificadores verbais, nove de $\mathrm{CN}$ e dezoito de gênero. A partir de critérios específicos para definirmos quais são os SCN (seção 3), testamos um conjunto de propriedades tipológicas que revelaram pontos de divergência e convergência entre os sistemas. Isso nos levou a inferir uma série de generalizações sobre SCN que indexam argumentos de uma oração. Acreditamos ter oferecido também uma metodologia de análise que permite, ao mesmo tempo, uma classificação dos tipos de sistemas e uma parametrização dos tipos de construções.

Ao final, acreditamos ter podido contribuir com a tipologia dos SCN e detalhar alguns dos sistemas da América do Sul que desafiam as propostas tipológicas existentes. 


\section{CHACON \& PRADO SATELES - EXPLORAÇÕES SOBRE PADRÕES...}

O trabalho também mostrou que parecem ser oportunas as análises de que na Amazônia haveria línguas com sistemas mistos de classificação nominal (Derbyshire e Payne 1990) e sistemas de CN menos gramaticalizados do que nas línguas Niger-Congo (Grinevald e Seifart 2004). Como resultado principal, chegamos a um conjunto de propriedades e tendências tipológicas que servem para contrastar num plano geral sistemas de gênero, $\mathrm{CN}$ e classificadores verbais. Ao propor o que seriam os protótipos destes sistemas, pudemos explicitar em que pontos outras línguas divergem dos mesmos. Algo para ser feito em estudos futuros é expandir nossa amostra e quantificar estatisticamente nossas análises.

Nossa discussão sobre os resultados nos levou a propor uma hipótese diacrônica para explicar diferenças entre sistemas prototípicos de gênero e $\mathrm{CN}$ com base em suas origens históricas distintas. É interessante, no entanto, que enquanto essa hipótese se sustenta nas diversas análises dos sistemas de gênero e $\mathrm{CN}$ pelas fontes primárias consultadas, além de evidências trans-linguísticas, há também aspectos que fazem os dois sistemas convergirem, principalmente em seu uso em sistemas de anáfora e concordância.

\section{Referências}

Aikhenvald, Alexandra Y. (2003a). A grammar of Tariana, from Northwest Amazonia (Cambridge Grammatica Descriptions). Cambridge: Cambridge University Press.

Aikhenvald, Alexandra Y. (2003b). Classifiers: A typology of noun categorization devices (Oxford Studies in Typology and Linguistic Theory). Oxford, New York: Oxford University Press.

Aikhenvald, Alexandra Y. (2007). Classifiers in multiple environments: Baniwa of Içana/Kurripako - A North Arawak perspective. International Journal of American Linguistics 73(4): 474-500.

https://doi.org/10.1086/523774

Aikhenvald, Alexandra Y. (2010). Gender, noun class and language obsolescence: The case of Paumarí. In Eithne B. Carlin; Simon van der Kerke (eds.). Linguistics and Archeology in the Americas: The Historization of Language and Society, vol. 2, pp. 235-252 (Brill's Studies in the Indigenous Languages of the Americas, 2). Leiden, The Netherlands: Brill. doi: https://doi.org/10.1163/9789047427087_014

Aikhenvald, Alexandra Y.; Green, Diana (1998). Palikur and the typology of classifiers. Anthropological Linguistics 40(3): 429-480.

Allan, Keith (1977). Classifiers. Language 53(2): 285-311. https://doi.org/10.1353/lan.1977.0045

Bickel, Balthasar (2010). Grammatical relations typology. In Jae Jung Song (ed.). The Oxford Handbook of Linguistic Typology, pp. 399-444. Oxford: Oxford University Press.

https://doi.org/10.1093/oxfordhb/9780199281251.013.0020

Birchall, Joshua (2014). Argument marking patterns in South American languages. LOT Publications. https://www.lotpublications.n1/Documents/352 fulltext.pdf

Birchall, Joshua (2016). Argument marking (ARGEx). In Muysken, Pieter et al. (eds.) South American Indian Language Structures (SAILS) Online. Leipzig: Online Max Planck Institute of Evolutionary Anthropology. (Available at http://sails.clld.org) 
Cerrón-Palomino, Rodolfo (2006). El chipaya o la lengua de los hombres del agua. Lima: Pontificia Universidad Católica del Perú.

Chacon, Thiago Costa. (2012). The phonology and morphology of Kubeo: The documentation, theory, and description of an Amazonian language (Ph.D. dissertation). University of Hawai'I at Manoa. http://www.ling.hawaii.edu/graduate/Dissertations/ThiagoChaconFinal.pdf

Chacon, Thiago Costa; Michael, Lev (2018) The evolution of subject-verb agreement in Eastern Tukanoan. Journal of Historical Linguistics 8(1): 59-94. https://doi.org/10.1075/jhl.16024.cha

Contini-Morava, Ellen; Kilarski, Marcin (2013). Functions of nominal classification. Language Sciences 40 (November): 263-299. https://doi.org/10.1016/j.langsci.2013.03.002

Corbett, Greville G. (1991). Gender. Cambridge: Cambridge University Press. https://doi.org/10.1017/CBO9781139166115

Corbett, Greville G. (2000). Number. Cambridge: Cambridge University Press.

Corbett, Greville G. (2006). Agreement. Cambridge: Cambridge University Press.

Cristofaro, Sonia (2013). The referential hierarchy: Reviewing the evidence in diachronic perspective. In Dik Bakker; Martin Haspelmath (eds.). Languages Across Boundaries. Studies in Memory of Anna Siewierska, pp. 69-94. Berlin, Boston: Mounton de Gruyter.

Croft, William (2017). Classifier constructions and their evolution: A commentary on Kemmerer (2016). Language, Cognition and Neuroscience 32(4): 425-427). https://doi.org/10.1080/23273798).2016).1253855

Croft, William A.; Denning, Keith; Kemmer, Suzanne (1990). Typology and diachrony in the work of Joseph H. Greenberg. In William A. Croft; Suzanne Kemmer; Keith Denning (eds.) Studies in Typology and Diachrony: Papers presented to Joseph H. Greenberg on his 75th birthday (Typological Studies in Language 20). John Benjamins. https://benjamins.com/catalog/tsl.20.02cro

Danielsen, Swintha (2007). Baure: An Arawak language of Bolivia. Leiden: Leiden University Press.

Derbyshire, Desmond; Payne, Doris L. (1990). Noun classification systems of Amazonian languages. In Doris L. Payne (ed.). Amazonian Linguistics: Studies in Lowland South American Languages, pp. 243-72. Austin, Texas: University of Texas Press.

DeLancey, Scott (1986). Towards a history of Tai classifier systems. In Colette G. Craig (ed.). Noun categorization (Typological Studies in Language 7), pp. 437-452. Amsterdam: John Benjamins Publishing Company. https://benjamins.com/catalog/tsl.7.26del

Dixon, R. M. W. (2011). The Jarawara language of Southern Amazonia. Oxford, New York: Oxford University Press.

Dixon, R. M. W. (1968). Noun Classes. Lingua 21: 104-125.

Estrada Ramírez, Hortensia (1996). La lengua Sáliba: Clases nominales y sistema de concordancia (Premios Nacionales de Cultura.) Santafé de Bogotá: Tercer Mundo Editores.

Everett, Daniel Leonard; Kern, Barbara (1997). Wari: The Pacaas Novos Language of Western Brazil. London; New York: Routledge. 


\section{CHACON \& PRADO SATELES - EXPLORAC̄̃̃ES SOBRE PADRÕES...}

Facundes, Sidney da Silva (2000). The language of the Apurinã people of Brazil (Maipure/Arawak) (Ph.D. dissertation). New York: State University of New York, Buffalo.

http://etnolinguistica.wdfiles.com/local--files/tese\%3Afacundes-2000/Facundes.pdf

Fedden, Sebastian; Corbett, Greville G. (2017). Gender and classifiers in concurrent systems: Refining the typology of nominal classification. Glossa: A Journal of General Linguistics 2(1): 34, 1-47.

https://doi.org/10.5334/gigl.177

Fernández Garay, Ana (1998). El Tehuelche, una lengua en vías de extinción (Estudios Filológicos). Chile: Universidad Austral de Chile.

Givón, T. (1986). Prototypes: Between Plato and Wittgenstein. In Colette G. Craig (ed.). Noun categorization (Typological Studies in Language 7), pp. 77-102 Amsterdam: John Benjamins Publishing Company. https://doi.org/10.1075/tsl.7.07giv

Givón, T. (2001). Syntax: An introduction. Volume I. Amsterdam: John Benjamins Publishing Company. https://doi.org/10.1075/z.syn5

Gomes, Dioney Moreira (2010). Classificação nominal em Mundurukú: Forma, função e tipologia. LIAMES: Linguas Indigenas Americanas 9(1): 7-25. https://doi.org/10.20396/liames.v9i1.1461

Greenberg, Joseph H. (1963). Some universals of grammar with particular reference to the order of meaningful elements. In Joseph H. Greenberg (ed.). Universals of Human Language, pp. 73-113. Cambridge, Mass: MIT Press.

Grinevald, Colette (2000). A morpho-syntactic typology of classifiers. In Gunter Senft (ed.). Systems of nominal classification, pp. 50-92. Cambridge: Cambridge University Press.

Grinevald, Colette (2002). Nominal classification in Movima of Bolivia. In Mily Crevels; Simon van de Kerke; Sérgio Meira; Hein van der Voort (eds.). Current studies on South American Indian languages: Selected papers from the 50th International Congress of Americanists in Warsaw and the Spinoza Workshop on Amerindian Languages in Leiden, 2000, pp. 215-239 (Indigenous languages of Latin America (ILLA) 3) Leiden: Research School of Asian, African, and Amerindian Studies (CNWs).

Grinevald, Colette (2015). Classifiers, linguistics of. In James D. Wright (ed.). International Encyclopedia of the Social \& Behavioral Sciences (Second Edition), pp. 811-818). Oxford: Elsevier. https://doi.org/10.1016/B978-0-08-097086-8).53003-5

Grinevald, Colette; Seifart, Frank (2004). Noun classes in African and Amazonian languages: Towards a comparison. Linguistic Typology 8 (2): 243-285). https://doi.org/10.1515/lity.2004.007

Haspelmath, Martin (2013). Argument indexing: A conceptual framework for the syntactic status of bound person forms. In Dik Bakker; Martin Haspelmath (eds.). Languages Across Boundaries (Studies in memory of Anna Wierswierska), pp. 197-226. Berlin, Boston: De Gruyter Mouton.

https://doir.org/10.1515/9783110331127

Haude, Katharina (2006). A grammar of Movima. Theses, Radboud Universiteit Nijmegen. https://tel.archives-ouvertes.fr/tel-00670611/document

Kilarski, Marcin (2013). Nominal classification: A history of its study from the Classical Period to the Present. Amsterdam Studies in the Theory and History of Linguistic Science. Series III, Studies in the History of the Language Sciences, volume 121. Amsterdam: John Benjamins Publishing Company. 
Krasnoukhova, Olga (2012). The noun phrase in the languages of South America (LOT Dissertation Series 301). Utrecht, The Netherlands: Radboud Universiteit Nigmegen. https://www.lotpublications.n1/Documents/301_fulltext.pdf

Krasnoukhova, Olga (2016). Noun Phrase (NP). In Muysken, Pieter et al. (eds.) South American Indian Language Structures (SAILS) Online. Leipzig: Online Max Planck Institute of Evolutionary Anthropology. (Available at http://sails.clld.org)

Pet, Willem J. A. (2011). A grammar sketch and lexicon of Arawak (Lokono Dian). Vol. 30. SIL E-Books. SIL International. e_Books_30_Pet_Arawak_Suriname.pdf

Queiroz, José Márcio Correia de (2012). Um estudo gramatical da língua Dzubukuá, familia Karirí (Tese de doutorado). João Pessoa: Universidade Federal da Paraíba. https://repositorio.ufpb.br/jspui/handle/tede/6358

Queixalós, Francisco (1998). Nom, verbe et prédicat en Sikuani (Colombie) (Langues et Sociétés d'Amérique traditionelle 6). Paris: Peeters Publishers.

Regúnaga, María Alejandra (2012). Tipología del género en lenguas indígenas de América del Sur. Bahía Blanca, Argentina: Editorial de la Universidad Nacional del Sur.

Rodrigues, Aryon D. (1997). Nominal classification in Karirí. Opción 22: 65-75.

Rosés Labrada, J. (2015). The Mako language: Vitality, grammar and classification (Thèse de Doctorat). University of Western Ontario \& Université Lumière-Lyon 2.

https://ir.lib.uwo.ca/cgi/viewcontent.cgi?article $=4280 \&$ context $=$ etd

Sakel, Jeanette (2004). A grammar of Mosetén. Berlin; New York: Mouton de Gruyter. http://public.eblib.com/choice/publicfullrecord.aspx?p=936880

Salzer, Meinke; Chapman, Shirley (1996). Dicionário bilingue nas línguas Paumarí e Portuguesa. [Porto Velho]: [Soc. Internacional de Lingüística]

Seifart, Frank (2005). The structure and use of shape-based noun classes in Miraña (Northwest Amazon). Radboud University. https://repository.ubn.ru.nl/handle/2066/26990

Serzisko, Fritz (1982). Gender, noun class and numeral classification: a scale of classificatory techniques. In René Dirven; Günter Radden (eds.). Issues in the theory of Universal Grammar. (Volumes 196-199), pp. 95-124. Tübingen: Gunter Narr Verlag

Silva, Léia De Jesus (2011). Morphosyntaxe du Rikbaktsa (Amazonie Brésilienne) (Thèse de doctorat en Linguistique théorique, descriptive et automatique).

http://www.theses.fr/2011PA070015

Van Gijn, Rik (2006). A grammar of Yurakaré. Radboud University Nijmegen. https://www.zora.uzh.ch/id/eprint/84700/1/gramofyu.pdf

Voort, Hein van der (2004). A grammar of Kwazá (Mouton Grammar Library 29). Berlin: Mouton de Gruyter.

Wheeler, Alva (1987). Gantëya bain (El pueblo siona del río Putumayo, Colombia) 2 vols. Instituto Lingüístico de Verano. https://www.sil.org/resources/publications/entry/18858 
CHACON \& PRADO SATELES - EXPLORAÇÕES SOBRE PADRÕES... Apêndice - Lista de Línguas, Fontes e Tipos de Sistemas de Classificação Nominal

\begin{tabular}{|c|c|c|c|c|c|}
\hline Lingua & Sistema & Semântica & $\begin{array}{l}\text { Número } \\
\text { de classes }\end{array}$ & $\begin{array}{l}\text { Indexa } \\
\text { argumentos? }\end{array}$ & Fonte \\
\hline Apurinã & Gênero & FEM VS. NFEM & 2 & $\operatorname{sim}$ & Facundes 2000 \\
\hline Apurinã & $\mathrm{CN}$ & PROPRIEDADE FÍSICA & 14 & $\operatorname{sim}$ & Facundes 2000 \\
\hline Baniwa & Gênero & FEM VS. NFEM & 2 & $\operatorname{sim}$ & Aikhenvald 2007 \\
\hline Baniwa & $\mathrm{CN}$ & SEXo, PROPRIEDADE FÍSICA & 44 & não & Aikhenvald 2007 \\
\hline Baure & Gênero & FEM VS. NFEM & 2 & $\operatorname{sim}$ & $\begin{array}{l}\text { Danielsen 2007, Kras- } \\
\text { noukhova } 2012\end{array}$ \\
\hline Baure & $\mathrm{CN}$ & $\begin{array}{l}\text { HUMANO, ANIMAL, PROPRIEDADE } \\
\text { FÍSICA }\end{array}$ & 10 & $\operatorname{sim}$ & $\begin{array}{l}\text { Danielsen 2007, Kras- } \\
\text { noukhova } 2012\end{array}$ \\
\hline Chipaya & Gênero & FEM VS. MSC & 2 & $\operatorname{sim}$ & Cerrón Palomino 2006 \\
\hline Jarawara & Gênero & FEM VS. MSC & 2 & $\operatorname{sim}$ & Dixon 2004 \\
\hline Jarawara & Gênero & AN. VS. IN & 2 & $\operatorname{sim}$ & Dixon 2004 \\
\hline Kariri & Gênero & AN VS. IN & 2 & não & \begin{tabular}{|l} 
Rodrigues \\
Queiroz 2012
\end{tabular} \\
\hline Kariri & $\begin{array}{l}\text { Classificadores } \\
\text { genitivos }\end{array}$ & COMIDA VS. OUTROS; & 12 & não & \begin{tabular}{|l} 
Rodrigues \\
Queiroz 2012
\end{tabular} \\
\hline Kariri & $\mathrm{CN}$ & PROPRIEDADE FÍSICA & 12 & não & \begin{tabular}{|l} 
Rodrigues \\
Queiroz 2012
\end{tabular} \\
\hline Kubeo & Gênero & FEM VS. MSC & 2 & $\operatorname{sim}$ & Chacon 2012 \\
\hline Kubeo & $\mathrm{CN}$ & PROPRIEDADE FÍSICA & 16 & não & Chacon 2012 \\
\hline Kwazá & $\mathrm{CN}$ & PROPRIEDADE FÍSICA & 150 & $\operatorname{sim}$ & van der Voort 2004 \\
\hline Lokono & Gênero & MSC VS. NMSC & 2 & $\operatorname{sim}$ & Pet 2011 \\
\hline Miraña & $\mathrm{CN}$ & SEXO, PROPRIEDADE FÍSICA & 18 & $\operatorname{sim}$ & Seifart 2005 \\
\hline Mosetén & Gênero & FEM VS. MSC & 2 & $\operatorname{sim}$ & $\begin{array}{l}\text { Sakel 2004, Krasnou- } \\
\text { khova } 2012\end{array}$ \\
\hline Movima & Gênero & FEM VS. MSC VS. NEU & 3 & $\operatorname{sim}$ & $\begin{array}{l}\text { Haude 2006, Grine- } \\
\text { vald } 2000\end{array}$ \\
\hline Movima & $\mathrm{CN}$ & PROPRIEDADE FÍSICA & 11 & $\operatorname{sim}$ & $\begin{array}{l}\text { Haude 2006, Grine- } \\
\text { vald } 2000\end{array}$ \\
\hline $\begin{array}{l}\text { Mundu- } \\
\text { rukú }\end{array}$ & $\mathrm{CN}$ & PROPRIEDADE FÍSICA & 8 & $\operatorname{sim}$ & Gomes 2009 \\
\hline Palikur & Gênero & FEM VS. MSC & 2 & $\operatorname{sim}$ & $\begin{array}{l}\text { Aikhenvald e Green } \\
1998\end{array}$ \\
\hline Palikur & Gênero & FEM VS. MSC VS. NEU & 3 & $\operatorname{sim}$ & $\begin{array}{l}\text { Aikhenvald e Green } \\
1998\end{array}$ \\
\hline Palikur & $\begin{array}{l}\text { Classificadores } \\
\text { genitivos }\end{array}$ & $\begin{array}{l}\text { FUNÇÃO (ANIMAL DOMÉSTICO VS. } \\
\text { CAÇA, ALIMENTOS, PLANTA, CRIAN- } \\
\text { ÇA) }\end{array}$ & 5 & não & $\begin{array}{l}\text { Aikhenvald e Green } \\
1998\end{array}$ \\
\hline Palikur & $\begin{array}{l}\text { Classificadores } \\
\text { Verbais }\end{array}$ & PROPRIEDADE FÍSICA & 11 & $\operatorname{sim}$ & $\begin{array}{l}\text { Aikhenvald e Green } \\
1998\end{array}$ \\
\hline Palikur & $\begin{array}{l}\text { Classificadores } \\
\text { numerais }\end{array}$ & SEXO, PROPRIEDADE FÍSICA & 11 & não & $\begin{array}{l}\text { Aikhenvald e Green } \\
1998\end{array}$ \\
\hline Paumari & $\mathrm{CN}$ & PROPRIEDADE FÍSICA & 2 & $\operatorname{sim}$ & $\begin{array}{l}\text { Aikhenvald 2010, Salzer } \\
\text { e Chapman } 1998\end{array}$ \\
\hline
\end{tabular}


LIAMES 19

\begin{tabular}{|c|c|c|c|c|c|}
\hline Paumari & Gênero & FEM VS. MSC & 2 & $\operatorname{sim}$ & $\begin{array}{l}\text { Aikhenvald 2010, Salzer } \\
\text { e Chapman } 1998\end{array}$ \\
\hline Rikbatsa & Gênero & FEM VS. MSC & 2 & não & Silva 2011 \\
\hline Rikbatsa & $\begin{array}{l}\text { Classificadores } \\
\text { Verbais }\end{array}$ & FORMA & 4 & $\operatorname{sim}$ & Silva 2011 \\
\hline Rikbatsa & $\begin{array}{l}\text { Classificadores } \\
\text { genitivos }\end{array}$ & $\begin{array}{l}\text { FUNÇÃO (ANIMAL DOMÉSTICO, ALI- } \\
\text { MENTOS) }\end{array}$ & 4 & não & Silva 2011 \\
\hline Sáliba & Gênero & FEM VS. NFEM & 2 & $\operatorname{sim}$ & $\begin{array}{ll}\text { Estrada } & \text { Ramirez } \\
\text { 1996; Rosés } & \text { Labrada } \\
2015 & \end{array}$ \\
\hline Sáliba & $\mathrm{CN}$ & PROPRIEDADE FÍSICA & 30 & $\operatorname{sim}$ & $\begin{array}{ll}\text { Estrada } & \text { Ramirez } \\
\text { 1996; Rosés Labrada } \\
2015\end{array}$ \\
\hline Sikuani & Gênero & FEM VS. MSC VS. NEU & 3 & não & Queixalos 1998 \\
\hline Sikuani & $\mathrm{CN}$ & PROPRIEDADE FÍSICA & 16 & não & Queixalos 1998 \\
\hline Siona & Gênero & FEM VS. NFEM & 2 & $\operatorname{sim}$ & Wheeler 1987 \\
\hline Siona & $\mathrm{CN}$ & PROPRIEDADE FÍSICA & 20 & não & Wheeler 1987 \\
\hline Tariana & Gênero & FEM VS. NFEM & 2 & $\operatorname{sim}$ & Aikhenvald 2003 \\
\hline Tariana & Gênero & AN VS. IN & 2 & não & Aikhenvald 2003 \\
\hline Tariana & $\mathrm{CN}$ & $\begin{array}{l}\text { SEXO, ANIMACIDADE, PROPRIEDADE } \\
\text { FÍSICA }\end{array}$ & 50 & $\operatorname{sim}$ & Aikhenvald 2003 \\
\hline Tehuelche & Gênero & FEM VS. MSC VS. NEU & 3 & $\operatorname{sim}$ & $\begin{array}{l}\text { Garay 1998, Krasnou- } \\
\text { khova } 2012\end{array}$ \\
\hline Wari & Gênero & FEM VS. MSC VS. NEU & 3 & $\operatorname{sim}$ & Everett \& Kern 1997 \\
\hline Yurakaré & - & - & 0 & não & van Gijn 2006 \\
\hline
\end{tabular}

Recebido: 12/6/2019

Versão revista e corrgida: 14/10/2019

Aceito: 22/10/2019.

LIAMES, Campinas, SP, v. 19, 1-35, e019016, 2019 